\title{
Journal of Applied Polymer Science
}

\author{
Volume 131, Issue 4,_February 15, 2014 \\ DOI: 10.1002/app.39902 \\ http://onlinelibrary.wiley.com/doi/10.1002/app.39902/abstract
}

\section{PLA/Lignocellulosic fiber composites: particle characteristics, interfacial adhesion and failure mechanism}

\author{
Gábor Faludi1 ${ }^{1,2}$, Gábor Dora $^{1,2}$, Balázs Imre ${ }^{1,2}$, Károly Renner ${ }^{1,2}$, János Móczó ${ }^{1,2}{ }^{*}$ and Béla Pukánszky $y^{1,2}$ \\ ${ }^{1}$ Laboratory of Plastics and Rubber Technology, Budapest University of Technology and Economics, $\mathrm{H}-$ \\ 1521 Budapest, P.O. Box 91, Hungary \\ ${ }^{2}$ Institute of Materials and Environmental Chemistry, Chemical Research Center, Hungarian Academy of \\ Sciences, H-1525 Budapest, P.O. Box 17, Hungary \\ *Corresponding author: Phone: +36-1-463-3477, Fax: +36-1-463-3474, Email: jmoczo@mail.bme.hu \\ ABSTRACT
}

PLA composites were prepared using six lignocellulosic fibers with widely varying particle characteristics. The composites were characterized by tensile testing, scanning electron (SEM) and polarization optical (POM) microscopy. Micromechanical deformation processes during loading were followed by acoustic emission measurements. Interfacial adhesion was estimated by three independent methods. Contrary to most claims published in the literature, interfacial adhesion between PLA and natural fibers was found to be rather strong, a result confirmed by the quantitative estimation of adhesion strength, acoustic emission measurements and SEM study. Strong interfacial adhesion results in weak dependence of the extent of reinforcement on the particle characteristics of the reinforcing fibers. Both acoustic emission measurements and microscopy indicated that the dominating micromechanical deformation process is 
the fracture of the fibers and close correlation was found between the initiation stress of fiber fracture, reinforcement and the ultimate strength of the composites.

KEYWORDS Biopolymers and Renewable Polymers, Cellulose and Other Wood Products, Composites, Mechanical Properties, Structure-Property Relations, Surfaces and Interfaces

\section{INTRODUCTION}

The interest in using polymeric materials derived from renewable resources increases by the day because of the considerably improved environmental conscientiousness of the society and the fear from the depletion of petrochemical based plastics ${ }^{1}$. Poly(lactic acid), PLA, seems to be the polymer which exploits the most successfully this surge of demand for such materials and satisfies the requirements of large scale processing and application at the same time. PLA has several advantages, among others it can be produced from renewable resources ${ }^{2}$ thus its application does not generate supplementary $\mathrm{CO}_{2}$ emission $^{3}$, it is recyclable and compostable, it has good stiffness and strength, and its properties can be modified and adjusted to a large number of applications in various ways ${ }^{4-6}$. On the other hand, this polymer has some drawbacks as well, including moisture sensitivity, fast physical ageing, poor impact resistance and relatively high price ${ }^{4,6}$. As a consequence, many attempts are made to modify it by plasticization $^{7-13}$, copolymerization ${ }^{14-19}$, blending ${ }^{20,21}$ or by the production of particulate filled or fiber reinforced composites ${ }^{11-13,23-31}$.

In the last decade many attempts were made to modify PLA with inorganic fillers or natural reinforcements. The structure of these latter materials is heterogeneous; it contains various phases and possesses one or more interfaces. Several factors determine the properties of such materials; one of the 
most important is interfacial adhesion. The question of interfacial adhesion was mentioned or expressively discussed in several papers, but the conclusions drawn are rather contradictory. The inorganic fillers studied included hydroxyapatite fibers or particles ${ }^{31-35}$, titanium dioxide ${ }^{36,37}$, zeolite ${ }^{38}$, calcium phosphate ${ }^{25}$ and sulphate ${ }^{13}$, calcium carbonate ${ }^{24,39,40}$, layered silicates ${ }^{41-47}$, expanded graphite ${ }^{47,48}$, graphene nanosheets ${ }^{49}$, carbon nanotubes ${ }^{50,51}$ and some other fillers or reinforcements ${ }^{52-54}$. Both weak and strong adhesion was found in these composites depending on the type of filler, surface modification, method of determination, etc., but the number of composites with good interfacial adhesion was more than twice as many ${ }^{13,31-33,35,37,40,45-50,52,55}$ as those with weak interaction ${ }^{24,25,36,40-43}$. These results indicate at least that PLA is capable of forming strong interaction with solid surfaces.

The picture becomes even more complicated when lignocellulosic fibers are used for reinforcement. The observations are occasionally contradictory even within the same paper. Plackett ${ }^{56}$ for example observed the increase of strength in PLA containing $40 \mathrm{wt} \%$ jute fabric compared to that of the neat matrix and explained it with good adhesion. On the other hand, he found voids around the fibers on SEM micrographs and concluded that adhesion must be improved. Similarly, Huda et al. ${ }^{57}$ deduced from the analysis of stiffness that interfacial adhesion is weak, but based on SEM micrographs they reasoned that adhesion must be strong, since no debonding was observed on the matrix/fiber interface and that failure was caused by matrix fracture. However, the analysis of papers available for us showed that based on their results most authors arrived to the conclusion that the interaction between PLA and lignocellulosic fibers is weak we,56-64. $^{26}$

We must consider here, however, that this conclusion was drawn mainly from the results of tensile tests ${ }^{56,58-60,62-64}$ and from SEM micrographs ${ }^{26,52,56-61,64}$. It was shown earlier that several micromechanical deformation processes take place during the deformation and failure of polymer/wood composites. These processes are competitive and they can often proceed also simultaneously. It is not very surprising therefore that micrographs taken from fracture surfaces are complex and difficult to 
interpret. Void formation indicating debonding, pull-out, and also fiber fracture are often observed simultaneously on them. The first two processes are easier to observe and interpret thus the conclusion that weak interaction develops between the components is almost evident. Similarly complicated is the interpretation of the composition dependence of tensile yield stress or tensile strength. Weak interfacial adhesion is often deduced from the fact that these mechanical properties decrease with increasing amount of the lignocellulosic fibers. We must keep in mind, however, that besides adhesion the extent of reinforcement depends also on other factors like matrix properties, aspect ratio and orientation. The composition dependence of strength cannot be interpreted without the consideration of these factors.

Egy nagy projekt keretében foglalkoztunk néhány partikuláris szerkezeti kérdéssel (65,66 FT400, KukoMech), de ez a kézirat általánosabb, az adhézióra vonatkozó értékes információkat tartalmaz. Considering all these apparent or real contradictions as well as the importance of interfacial interactions in the determination of composite properties one of the goals of this study was the estimation of the strength of adhesion between lignocellulosic fibers and PLA. To achieve this goal we prepared composites with six different reinforcements of widely varying chemical composition and particle characteristics. We made an attempt to determine the failure mechanism of the composites, a question rarely discussed in literature. Finally, the practical consequence of adhesion and deformation mechanism is discussed in the final section of the paper.

\section{EXPERIMENTAL}

The PLA used in the experiments was obtained from NatureWorks (USA). The selected grade (Ingeo 4032D, $M_{n}=88500 \mathrm{~g} / \mathrm{mol}$ and $\left.M_{w} / M_{n}=1.8\right)$ is recommended for extrusion. The polymer (<2\% $D$ isomer) has a density of $1.24 \mathrm{~g} / \mathrm{cm}^{3}$, while its $\mathrm{MFI}$ is $3.9 \mathrm{~g} / 10 \mathrm{~min}$ at $190{ }^{\circ} \mathrm{C}$ and $2.16 \mathrm{~kg}$ load. Six lignocellulosic fibers were used as reinforcements in the study: four wood fibers, microcrystalline cellulose and the heavy 
fraction of grinded corn cob. Because of their importance particle characteristics of the fibers were characterized quite thoroughly. The SEM micrographs presented in Fig. 1 show the fillers used. Particle size and aspect ratio change in a wide range. Particle characteristics were determined quantitatively by laser light scattering, but also by image analysis from the SEM micrographs. The results are compiled in Table 1. Since in an earlier study we found that aspect ratio is one of the most important characteristics determining composite properties, we include this information into the abbreviation of the fibers in order to facilitate discussion. The letters indicate the origin of the fibers, while the numbers correspond to ten times the aspect ratio (see Table 1).

Both poly(lactic acid) and the fibers were dried in a vacuum oven before composite preparation $\left(110^{\circ} \mathrm{C}\right.$ for 4 hours and $105^{\circ} \mathrm{C}$ for 4 hours, respectively). The components were homogenized using a Brabender W $50 \mathrm{EHT}$ internal mixer at $180^{\circ} \mathrm{C}, 50 \mathrm{rpm}$ for $10 \mathrm{~min}$. Wood content changed in a relative wide range, composites contained 5, 10, 15, 20, 30, 40, 50 and 60 vol\% lignocellulosic fibers. The homogenized material was compression molded into $1 \mathrm{~mm}$ thick plates at $190{ }^{\circ} \mathrm{C}$ using a Fontijne SRA 100 machine. All specimens were kept in a room with controlled temperature and humidity $\left(23^{\circ} \mathrm{C}\right.$ and $\left.50 \%\right)$ for at least one week prior further testing.

Mechanical properties were characterized by the tensile testing of specimens cut from the $1 \mathrm{~mm}$ thick plates using an Instron 5566 apparatus. The measurements were done at $5 \mathrm{~mm} / \mathrm{min}$ cross-head speed and $115 \mathrm{~mm}$ gauge length. Micromechanical deformation processes were followed by acoustic emission (AE) measurements. A Sensophone AED 40/4 apparatus was used to record and analyze acoustic signals during tensile tests. The particle characteristics of wood and the structure, as well as the deformation mechanism of the composites were studied by scanning electron microscopy, SEM (JEOL JSM-6380 LA). Micrographs were recorded on tensile fracture surfaces. Failure mechanism was studied also on model composites by polarization optical microscopy (POM). Thin (about $150 \mu \mathrm{m}$ ) films were 
compression molded from the composites, fractured by tensile testing and the broken halves were studied in the microscope to determine failure mode.

\section{RESULTS AND DISCUSSION}

The morphology of PLA/lignocellulosic composites can be relatively complicated. The polymer can crystallize, but the rate of crystallization is rather slow thus under the conditions of normal processing operations it remains mostly amorphous; its crystalline content is very small. Besides crystalline structure, the distribution of the fibers in the matrix, i.e. the possible formation of aggregates, especially at large fiber loadings, is also an important issue. The fiber might influence also interphase formation and the mobility of the polymer molecules. We investigated these questions in previous a study in detail ${ }^{65}$. We found that crystallinity is negligible in PLA, while in PP/wood composites limited aggregation resulted from the mere physical contact of the particles due to geometrical reasons ${ }^{66}$. As a consequence we refrain from the detailed discussion of structure and focus mostly on properties, micromechanical deformations, interfacial adhesion, and deformation and failure mechanism. Consequences for practice are discussed in the final section of the paper.

\section{Properties, reinforcement}

The properties of the composites change with fiber content according to the expectations and in agreement with literature references. Stiffness increases from 3.4 GPa of the matrix to about $7 \mathrm{GPa}$ of the composite with the largest fiber content (not shown). The effect of particle characteristics is slight, only the composite containing the fiber with the largest aspect ratio (W126) has distinctly larger stiffness than 
the rest of the composites. Structural effects are not reflected by the composition dependence of stiffness, a small extent of aggregation might be detected at the largest wood content at most.

The characteristics of the reinforcement influence tensile strength much more significantly, as shown in Fig. 2. Tensile strength decreases with increasing fiber content for all reinforcements, but the decrease is relatively moderate for the thin long fibers (W126) and for the wood having the smallest particle size (W35, $40 \mu \mathrm{m})$. Composites prepared from corn cob have the smallest strength and the rest of the composites are located between these two boundary cases. The results indicate that both aspect ratio and particle size influence composite strength, and large reinforcement can be achieved with large aspect ratio and small size.

From the decrease of strength with increasing fiber content several groups deduced that interfacial adhesion is weak in PLA/wood composites ${ }^{57-60,62,63}$. This conclusion can be further supported by the comparison of PLA composites with PP/wood composites. Adhesion is poor between PP and wood and without a coupling agent, composite strength decreases with increasing fiber content. On the other hand, if we add a coupling agent like maleated polypropylene (MAPP) to the composite, strength increases considerably with fiber content, i.e. from about $17 \mathrm{MPa}$ to $41 \mathrm{MPa}$ in a PP random copolymer ${ }^{67}$. We must consider here, however, that reinforcement depends also on the properties of the matrix; it decreases with increasing matrix stiffness and strength. The PP mentioned above had a strength of $17 \mathrm{MPa}$, while the strength of our PLA is close to $60 \mathrm{MPa}$. As a consequence, the strength of interfacial adhesion cannot be deduced directly from such a comparison of different materials or from the composition dependence of mechanical properties.

On the other hand, the extent of reinforcement can be estimated quantitatively with the help of simple models. The dependence of tensile strength on filler content can be expressed as ${ }^{68}$

$$
\sigma_{T}=\sigma_{T 0} \lambda^{n} \frac{1-\varphi}{1+2.5 \varphi} \exp (B \varphi)
$$


where $\sigma_{\mathrm{T}}$ and $\sigma_{\text {то }}$ are the true tensile strength of the composite and the matrix, respectively $\left(\sigma_{\mathrm{T}}=\sigma \lambda\right.$ and $\left.\lambda=L / L_{0}\right), \lambda$ is relative elongation $\left(\lambda=L / L_{0}\right.$, where $L_{0}$ is gauge length and $L$ the length measured at the moment of failure), $\mathrm{n}$ is a parameter expressing the strain hardening tendency of the matrix, $\phi$ is the volume fraction of the fiber and B is related to its relative load-bearing capacity, i.e. to the extent of reinforcement, which depends among other factors also on interfacial interaction. We can write Eq. 1 in linear form

$$
\ln \sigma_{\text {Tred }}=\ln \frac{\sigma_{T}(1+2.5 \varphi)}{\lambda^{n}(1-\varphi)}=\ln \sigma_{T 0}+B \varphi
$$

and the plot of the natural logarithm of reduced tensile strength against fiber content should result in a linear correlation, the slope of which is proportional to the load-bearing capacity of the reinforcement and under certain conditions to the strength of interaction. In Fig. 3 the strength of three series of composites is plotted against filler content in the form indicated by Eq. 2. We obtain linear correlations with different slopes indeed indicating dissimilar reinforcing effect of the fibers. The fibers were selected to show the extremes of reinforcement and an additional fiber for comparison. Rather surprisingly the reinforcement achieved by the six fibers differs from each other only very little. If we use PP as comparison again, changing adhesion resulted in an increase from 1.1 to 5.3 there ${ }^{69}$, while B values change from 1.7 to 2.6 in the PLA matrix. The extent of reinforcement is shown quantitatively for all composites in Table 2. If we compare the values to the particle characteristics listed in Table 1 we see that small aspect ratio results in small reinforcement $(C C 23, A R=2.3)$, while small size $(\mathrm{W} 35,40 \mu \mathrm{m})$ and large aspect ratio $(\mathrm{W} 126$, $A R=12.6)$ leads to stronger reinforcement. The small differences and the limited effect of particle characteristics on reinforcement are quite surprising. This observation is further supported by Fig. 4 in which parameter B expressing reinforcement is plotted against the aspect ratio of the fibers. This characteristic had the most pronounced effect on reinforcement in PP/wood composites ${ }^{65}$, but the effect depended also on adhesion; it was much weaker at good than at poor adhesion. We might deduce from 
this comparison that interfacial adhesion might be stronger in PLA/wood composites than indicated in a

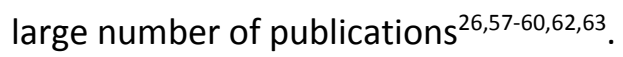

\section{Micromechanical deformations}

Because of the dissimilar elastic properties of the matrix polymer and the inclusion, stress concentration develops around this latter in heterogeneous polymers. Local stress maxima initiate local deformation processes some of which are accompanied by acoustic events. Sound waves can be picked up by microphones and the analysis of the signals may yield valuable information about the deformation and failure of the material. The result of an acoustic measurement carried out on a PLA/wood composite is presented in Fig. 5. Each small circle is an acoustic event the amplitude of which can be deduced from the right hand axis of the graph. The corresponding stress vs. strain trace is also shown as reference. We can see that significant acoustic activity starts above a certain deformation and that amplitudes cover a wide range. Further conclusion is difficult to deduce from individual signals, additional analysis is needed in order to extract more information from the results. The cumulative number of signals is plotted as a function of deformation in Fig. 6 together with the stress vs. strain trace. We see that acoustic activity increases continuously until the failure of the composite. We can determine characteristic deformation and stress values related to the initiation of the dominating micromechanical deformation mechanism.

Cumulative number of signal traces are plotted for all composites containing the various fibers in 10 vol\% in Fig. 7. The traces are very similar to each other; they differ only in the total number of signals detected until failure, and in initiation deformation. The trace recorded on the composite containing corn cob shows an additional difference, it has a shoulder (shown by an arrow) at small elongations indicating the occurrence of an additional deformation process. The shape of the cumulative number of signal vs. elongation traces could be related to the mechanism of deformation earlier ${ }^{67,69,70}$. Traces similar to those 
shown in Fig. 7 were obtained on composites with strong interfacial adhesion in which fiber fracture was the dominating mechanism. In the case of particulate filled composites, in which debonding is the only deformation process, step-like traces approaching a plateau value were recorded in all matrices including $\mathrm{PLA}^{71,72}$. The shape of the traces indicates stronger PLA/fiber adhesion than claimed by literature references.

Characteristic stresses derived from the cumulative number of signal vs. deformation and the corresponding stress vs. deformation traces are plotted in Fig. 8 for all composites. According to the two steps, two characteristic values were determined for corn cob indicated by empty (first step) and full (second step) symbols in the figure. The composites can be divided into three groups. Probably not very surprisingly, the wood with small particle size (W35) and the one having large aspect ratio (W126) forms one group with the largest characteristic stress, while corn cob forms a group of its own. The rest of the fibers behave very similarly. These results clearly prove that the dominating micromechanical deformation process occurring during the deformation of PLA/wood composites depend on the particle characteristics of the reinforcement. In Fig. 9 the characteristic stress derived from acoustic emission measurements at 20 vol\% fiber content is plotted against the extent of reinforcement determined from tensile strength. Apart from the value for corn cob, the correlation is extremely close indicating that macroscopic composite properties depend very much on the micromechanical process taking place in the composite during deformation. The behavior of corn cob must be studied more in detail in the future.

\section{Interfacial adhesion}

In particulate filled and especially in short fiber reinforced composites the direct determination of interfacial adhesion is difficult. We mentioned earlier that conclusions drawn from the analysis of SEM micrographs are very uncertain because a number of processes can take place simultaneously (debonding, 
fiber pull-out, fiber fracture), because of the limited area studied, and because SEM cannot supply quantitative values for adhesion anyway. The other frequently used approach, the composition dependence of tensile strength can be also misleading because of the simultaneous effect of several factors (matrix properties, adhesion, orientation, aspect ratio).

Different approaches can be used for the estimation of interfacial adhesion in particulate filled polymers. The first is based on surface energy and the calculation of the reversible work of adhesion

$$
W_{A B}=2\left(\gamma_{1}^{d} \gamma_{2}^{d}\right)^{1 / 2}+2\left(\gamma_{1}^{p} \gamma_{2}^{p}\right)^{1 / 2}
$$

where $\gamma_{1}{ }^{d}$ and $\gamma_{2}{ }^{d}$ are the dispersion, while $\gamma_{1}{ }^{p}$ and $\gamma_{2}{ }^{p}$ the polar component of surface tension for components 1 and 2, respectively. The more accurate approach of using acid-base interactions for the determination of the reversible work of adhesion cannot be used in our composites because we do not know the number of interacting acid-base sites located on the surface that is necessary for the calculation $^{73}$. The reversible work of adhesion was shown to correlate closely with reinforcement ${ }^{74}$. Another approach for the estimation of the strength of interfacial adhesion is based on the determination of debonding stress by acoustic emission measurements ${ }^{75}$. Debonding stress is defined as ${ }^{76}$

$$
\sigma^{D}=-C_{1} \sigma^{T}+C_{2}\left(\frac{E W_{A B}}{R}\right)^{1 / 2}
$$

where $\sigma^{\mathrm{D}}$ and $\sigma^{\top}$ are debonding and thermal stresses, respectively, E the Young's modulus of the matrix, WAB the reversible work of adhesion, $R$ the radius of the particles, while $C_{1}$ and $C_{2}$ are geometric constants related to the debonding process. If we know the parameters of the equation, which were calculated from measurements done on polymer/filler pairs with known characteristics $\left(E, R, W_{A B}\right)$, the stiffness of the matrix and the size of the particles, which we usually do, we can calculate the strength of adhesion. We term this quantity $\mathrm{Fa}$ instead of $\mathrm{W}_{\mathrm{AB}}$ in order to differentiate the approach used for determination. Finally, the strength of interfacial adhesion can be also estimated from the composition dependence of composite 
strength with the model presented above (see Eq. 1), if the dominating deformation mechanism is debonding.

Unfortunately all three approaches can be used only with serious limitations in our PLA/wood composites. Eq. 3 does not estimate specific interactions very accurately, although we expect the formation of such between the carbonyl groups of PLA and the hydroxyl groups of the cellulose. The approach expressed in Eq. 4 assumes spherical particles and debonding as the dominating process and neither is fulfilled in our case. Finally, failure mechanism and particle shape are important factors also in the third approach; parameter B offers information about reinforcement, but the estimation of interfacial adhesion is questionable. Nevertheless, in lack of better solution we applied all three approaches to our composites and the results are compiled in Table 3. Similar calculations were carried out also for PP/wood and PVC/wood composites to facilitate interpretation. We can see that all three approaches indicate stronger adhesion in PLA/wood than in PP/wood composites. Surprisingly, the strongest adhesion develops in PVC composites. The same filler, corn cob, was used as reinforcement in all three matrices. In spite of their serious limitations and uncertainty, none of the approaches indicate weak, but at least intermediate interaction in PLA/wood composites. We should like to remind the reader here that debonding and pull-out are the dominating micromechanical deformation processes in PP/wood composites when adhesion is poor and fiber fracture occurs at good adhesion ${ }^{66}$. As a consequence, we can expect any one of them or both in our PLA/wood composites.

We made an additional attempt to estimate the level of adhesion and to compare different polymer/wood composites. As mentioned before, the value of parameter B, i.e. reinforcement depends also on the properties of the matrix (see Eq. 2). In order to compensate for this effect we weighed parameter B with the yield stress of the matrix and plotted this corrected value, $B_{c}$, against matrix yield stress in Fig. 10. Values obtained for $\mathrm{CaCO}_{3}$ composites prepared with different matrices are also plotted as comparison. We can see that the values are very similar for the latter, almost independently of the 
matrix polymer. We can distinguish two groups in the case of wood composites. The values obtained at poor adhesion in PP are significantly smaller than in any of the other cases, which are similar for PP homopolymer and random copolymer at good adhesion, PVC and PLA. Variation within a group of the same matrix is caused by the effect of other factors influencing reinforcement, i.e. aspect ratio, orientation, particle size, etc. We must draw the conclusion that adhesion is very similar in these composites and we know that it is strong in PP composites containing a MAPP coupling agent. Practically all evidence indicates that contrary to claims published in the literature interfacial adhesion is not weak in PLA/wood composites, but considerable specific interactions develop between the components.

\section{Failure mechanism, consequence}

Based on the considerations presented above we came to the final conclusion that adhesion is relatively strong between lignocellulosic fibers and the PLA matrix. Moreover, the shape of the cumulative number of signal vs. deformation traces differed from that observed in cases when debonding was the dominating micromechanical deformation process ${ }^{67,69,71,77}$. SEM micrographs were prepared to reveal or at least supply some additional information about the mechanism of failure in our PLA/wood composites.

Fig. 11 shows such a micrograph which is typical for most of the composites studied. The dominating process is definitely fiber fracture with a limited number of debonding and fiber pull-out events. However, the number of these latter is much smaller than that of fiber fracture. This observation agrees quite well with the fact that very similar cumulative number of signal vs. deformation traces were obtained in PP/wood composites with good adhesion ${ }^{67,70}$ as those shown in Fig. 7. The fact of fiber fracture was strongly supported and verified also by the POM study. Selected micrographs are shown in Fig. 12. In composites containing large particles oriented perpendicularly to the direction of the load, always the fiber fractures leading to the failure of the composite itself. Failure might be different for small and/or 
thin fibers, like W35 and W126. The only lignocellulosic filler which behaved differently was corn cob. Extensive particle fracture could be observed in this material as well (see Fig. 13a), but the presence of other mechanisms was also detected. As Fig. 13b shows certain particles debond from the matrix forming voids around them. Either this mechanism or the fracture of weaker particles may result in the shoulder appearing on the cumulative number of signal vs. deformation trace of composites containing corn cob in Fig. 7. The phenomenon needs further measurements and study.

Finally we must discuss the influence of the dominating micromechanical deformation process on the macroscopic properties and performance of the composites. Composite strength is plotted against the characteristic stress determined by acoustic emission in Fig. 14. Extremely close correlation exists between the two quantities indicating that processes occurring around the particles determine the performance of the composite. The similar values also show that the fracture of wood particles leads to the catastrophic failure of the composite thus further improvement in composite properties is possible only by the increase of the inherent strength of wood or in a limited extent by the proper selection of the particle characteristics of the reinforcement (see W35 and W126).

\section{CONCLUSIONS}

The study of deformation and failure mechanisms as well as interfacial interactions in PLA/lignocellulosic fiber composites indicated that contrary to most claims published in the literature, interfacial adhesion is rather strong between PLA and natural fibers. This conclusion was confirmed by three independent approaches used for the quantitative estimation of the strength of interfacial interactions, by acoustic emission measurements and by SEM study. Strong interfacial adhesion results in weak dependence of the extent of reinforcement on the particle characteristics of the reinforcing fibers. Both acoustic emission measurements and microscopy indicated that the dominating micromechanical 
deformation mechanism is the fracture of the fibers and close correlation was found between the initiation stress of fiber fracture, reinforcement and ultimate composite strength. Corn cob behaved differently from the rest of the reinforcements used, at least two consecutive deformations were detected during the loading of its composites. Further study is needed to identify these unambiguously.

\section{ACKNOWLEDGEMENTS}

The authors are indebted to Zsolt László for his help in the determination of the particle characteristics of wood. The research on heterogeneous polymer systems was financed by the National Scientific Research Fund of Hungary (OTKA Grant No. K 101124) and by the Forbioplast FP7 project of EU (212239); we appreciate the support very much. One of the authors (KR) is grateful also to the János Bolyai Research Scholarship of the Hungarian Academy of Sciences.

\section{REFERENCES AND NOTES}

1. Markarian, J. Plastics, Additives and Compounding 2008, 10, 22-25.

2. Sawyer, D. J. Macromol. Symp. 2003, 201, 271-282.

3. Dorgan, J. R.; Lehermeier, H. J.; Palade, L.-I.; Cicero, J. Macromol. Symp. 2001, 175, 55-66.

4. Auras, R.; Harte, B.; Selke, S. Macromol. Biosci. 2004, 4, 835-864.

5. Kale, G.; Auras, R.; Singh, S. P.; Narayan, R. Polym. Test 2007, 26, 1049-1061. 
6. Perego, G.; Cella, G. D. In Poly(lactic acid): Synthesis, Structures, Properties, Processing, and Applications; Auras, R.; Lim, L.-T.; Selke, S.; Tsuji, H., Eds.; John Wiley \& Sons, Inc.: Hoboken, New Jersey, 2010; pp 141-153.

7. Lemmouchi, Y.; Murariu, M.; Dos Santos, A. M.; Amass, A. J.; Schacht, E.; Dubois, P. Eur. Polym. J. $2009,45,2839-2848$

8. Pillin, I.; Montrelay, N.; Grohens, Y. Polymer 2006, 47, 4676-4682.

9. Martin, O.; Avérous, L. Polymer 2001, 42, 6209-6219.

10. Ljungberg, N.; Wesslen, B. Polymer 2003, 44, 7679-7688.

11. Wang, N.; Zhang, X. X.; Ma, X. F.; Fang, J. M. Polym. Degrad. Stabil. 2008, 93, 1044-1052.

12. Paul, M. A.; Alexandre, M.; Degee, P.; Henrist, C.; Rulmont, A.; Dubois, P. Polymer 2003, 44, 443450.

13. Murariu, M.; Ferreira, A. D.; Pluta, M.; Bonnaud, L.; Alexandre, M.; Dubois, P. Eur. Polym. J. 2008, $44,3842-3852$.

14. Li, B.; Chen, S. C.; Qiu, Z. C.; Yang, Q. K. K.; Tang, S. P.; Yu, W. J.; Wang, Y. Z. Polym. Bull. 2008, 61, 139-146.

15. Hirata, M.; Kimura, Y. Polymer 2008, 49, 2656-2661.

16. Ho, C. H.; Wang, C. H.; Lin, C. I.; Lee, Y. D. Polymer 2008, 49, 3902-3910.

17. Mert, O.; Doganci, E.; Erbil, H. Y.; Dernir, A. S. Langmuir 2008, 24, 749-757.

18. Södergard, A.; Stolt, M. Prog. Polym. Sci. 2002, 27, 1123-1163.

19. Nagahama, K.; Nishimura, Y.; Ohya, Y.; Ouchi, T. Polymer 2007, 48, 2649-2658.

20. Gu, S. Y.; Zhang, K.; Ren, J.; Zhan, H. Carbohydr. Polym. 2008, 74, 79-85.

21. Rohman, G.; Laupretre, F.; Boileau, S.; Guerin, P.; Grande, D. Polymer 2007, 48, 7017-7028.

22. Bhat, G. S.; Gulgunje, P.; Desai, K. Express Polym. Lett. 2008, 2, 49-56.

23. Pluta, M.; Jeszka, J. K.; Boiteux, G. Eur. Polym. J. 2007, 43, 2819-2835. 
24. Gorna, K.; Hund, M.; Vucak, M.; Grohn, F.; Wegner, G. Mater. Sci. Eng. A: 2008, 477, 217-225.

25. Bleach, N. C.; Nazhat, S. N.; Tanner, K. E.; Kellomaki, M.; Törmala, P. Biomaterials 2002, 23, 1579-1585.

26. Bax, B.; Müssig, J. Compos. Sci. Technol. 2008, 68, 1601-1607.

27. Kuan, C. F.; Kuan, H. C.; Ma, C. C. M.; Chen, C. H. J. Phys. Chem. Solids 2008, 69, 1395-1398.

28. Murariu, M.; Ferreira, A. D.; Degee, P.; Alexandre, M.; Dubois, P. Polymer 2007, 48, 2613-2618.

29. Pluta, M.; Murariu, M.; Ferreira, A. D.; Alexandre, M.; Galeski, A.; Dubois, P. J. Polym. Sci. Pt. BPolym. Phys. 2007, 45, 2770-2780.

30. Sobkowicz, M. J.; Feaver, J. L.; Dorgan, J. R. Clean-Soil Air Water 2008, 36, 706-713.

31. Kasuga, T.; Ota, Y.; Nogami, M.; Abe, Y. Biomaterials 2001, 22, 19-23.

32. Lin, P.-L.; Fang, H.-W.; Tseng, T.; Lee, W.-H. Materials Letters 2007, 61, 3009-3013.

33. Russias, J.; Saiz, E.; Nalla, R. K.; Gryn, K.; Ritchie, R. O.; Tomsia, A. P. Mater. Sci. Eng: C 2006, 26, 1289-1295.

34. Wang, X.; Song, G.; Lou, T. Med. Eng. Phys. 2010, 32, 391-397.

35. Li, J.; X.L.Lu; Zheng, Y. F. Appl. Surf. Sci. 2008, 255, 494-497.

36. Nakayama, N.; Hayashi, T. Polym. Degrad. Stabil. 2007, 92, 1255-1264.

37. Luo, Y.-B.; Li, W.-D.; Wang, X.-L.; Xu, D.-Y.; Wang, Y.-Z. Acta Materialia 2009, 57, 3182-3191.

38. Yuzay, I. E.; Auras, R.; Soto-Valdez, H.; Selke, S. Polym. Degrad. Stabil. 2010, 95, 1769-1777.

39. Kasuga, T.; Maeda, H.; Kato, K.; Nogami, M.; Hata, K.-i.; Ueda, M. Biomaterials 2003, 24, 32473253.

40. Jiang, L.; Zhang, J.; Wolcott, M. P. Polymer 2007, 48, 7632-7644.

41. Li, B.; Dong, F.-X.; Wang, X.-L.; Yang, J.; Wang, D.-Y.; Wang, Y.-Z. Eur. Polym. J. 2009, 45, 29963003.

42. Rhim, J.-W.; Hong, S.-I.; Ha, C.-S. LWT - Food Sci. Technol. 2009, 42, 612-617. 
43. Chang, J.-H.; An, Y. U.; Cho, D.; Giannelis, E. P. Polymer 2003, 44, 3715-3720.

44. Kim, M. W.; Song, Y. S.; Youn, J. R. Compos. Part A 2010, 41, 1817-1822.

45. Fukushima, K.; Tabuani, D.; Camino, G. Mater. Sci. Eng.: C 2009, 29, 1433-1441.

46. Marras, S. I.; Zuburtikudis, I.; Panayiotou, C. Eur. Polym. J. 2007, 43, 2191-2206.

47. Fukushima, K.; Murariu, M.; Camino, G.; Dubois, P. Polym. Degrad. Stabil. 2010, 95, 1063-1076.

48. Murariu, M.; Dechief, A. L.; Bonnaud, L.; Paint, Y.; Gallos, A.; Fontaine, G.; Bourbigot, S.; Dubois, P. Polym. Degrad. Stabil. 2010, 95, 889-900.

49. Cao, Y.; Feng, J.; Wu, P. Carbon 2010, 48, 3834-3839.

50. Villmow, T.; Pötschke, P.; Pegel, S.; Häussler, L.; Kretzschmar, B. Polymer 2008, 49, 3500-3509.

51. Kuan, C.-F.; Kuan, H.-C.; Ma, C.-C. M.; Chen, C.-H. J. Phys. Chem. Solids 2008, 69, 1395-1398.

52. Wang, N.; Zhang, X.; Ma, X.; Fang, J. Polym. Degrad. Stabil. 2008, 93, 1044-1052.

53. Zhao, Y.-Q.; Lau, K.-T.; Kim, J.-k.; Xu, C.-L.; Zhao, D.-D.; Li, H.-L. Compos. Part B: 2010, 41, 646653.

54. Li, H.; Huneault, M. A. Polymer 2007, 48, 6855-6866.

55. Huda, M. S.; Drzal, L. T.; Mohanty, A. K.; Misra, M. Compos. Part B: 2007, 38, 367-379.

56. Plackett, D.; Løgstrup Andersen, T.; Batsberg Pedersen, W.; Nielsen, L. Compos. Sci. Technol. $2003,63,1287-1296$

57. Huda, M. S.; Drzal, L. T.; Misra, M.; Mohanty, A. K. J. Appl. Polym. Sci. 2006, 102, 4856-4869.

58. Huda, M. S.; Mohanty, A. K.; Drzal, L. T.; Schut, E.; Misra, M. J. Mater. Sci. 2005, 40, 4221-4229.

59. Mathew, A. P.; Oksman, K.; Sain, M. J. Appl. Polym. Sci. 2005, 97, 2014-2025.

60. Oksman, K.; Skrifvars, M.; Selin, J.-F. Compos. Sci. Technol. 2003, 63, 1317-1324.

61. Bledzki, A. K.; Jaszkiewicz, A.; Scherzer, D. Compos. Part A: 2009, 40, 404-412.

62. Petinakis, E.; Yu, L.; Edward, G.; Dean, K.; Liu, H. S.; Scully, A. D. J. Polym. Environ. 2009, 17, 8394. 
63. Sykacek, E.; Hrabalova, M.; Frech, H.; Mundigler, N. Compos. Part A: 2009, 40, 1272-1282.

64. Suryanegara, L.; Nakagaito, A. N.; Yano, H. Compos. Sci. Technol. 2009, 69, 1187-1192.

65. Molnár, K.; Móczó, J.; Murariu, M.; Dubois, P.; Pukánszky, B. Express Polym. Lett. 2009, 3, 49-61.

66. Dányádi, L.; Janecska, T.; Szabo, Z.; Nagy, G.; Móczó, J.; Pukánszky, B. Compos. Sci. Technol. $2007,67,2838-2846$

67. Renner, K.; Móczó, J.; v, B. Compos. Sci. Technol. 2009, 69, 1653-1659.

68. Pukánszky, B. Compos. 1990, 21, 255-262.

69. Renner, K.; Kenyó, C.; Móczó, J.; Pukánszky, B. Compos. Part A: 2010, 41, 1653-1661.

70. Dányádi, L.; Renner, K.; Móczó, J.; Pukánszky, B. Polym. Eng. Sci. 2007, 47, 1246-1255.

71. Renner, K.; Yang, M. S.; Móczó, J.; Choi, H. J.; Pukánszky, B. Eur. Polym. J. 2005, 41, 2520-2529.

72. Imre, B.; Keledi, G.; Renner, K.; Móczó, J.; Murariu, M.; Dubois, P.; Pukánszky, B. Carbohydr. Polym. 2012, 89, 759- 767

73. Fowkes, F. M. J. Adhes. Sci. Technol. 1987, 1, 7-27.

74. Vörös, G.; Fekete, E.; Pukánszky, B. J. Adhes. 1997, 64, 229-250.

75. Renner, K.; Móczó, J.; Vörös, G.; Pukánszky, B. Eur. Polym. J. 2010, 46, 2000-2004.

76. Pukánszky, B.; Vörös, G. Compos. Interfaces 1993, 1, 411-427.

77. Renner, K.; Móczó, J.; Suba, P.; Pukánszky, B. Compos. Sci. Technol. 2010, 70, 1141-1147.

Figure Caption.

Fig. 1 Particle characteristics of the studied lignocellulosic fibers (SEM micrographs); a) corn cob (CC23), b) Vivapur MCC (MC29), c) Arbocel CW 630 (W35), d) Lasole 200/150 (W54), e) Filtracel EFC 1000 (W68), f) Arbocel FT 400 (W126). 
Fig. 2 Effect of the type and amount of reinforcement on the tensile strength of PLA/lignocellulosic fiber composites. Symbols: $(\Delta)$ CC23, $(\nabla)$ MC29, $(\diamond)$ W35, $(\triangleleft)$ W54, $(\square)$ W68, (O) W126.

Fig. 3 Reduced tensile strength of selected composites plotted against fiber content according to Eq. 2. Symbols are the same as in Fig. 2.

Fig. 4 Correlation between the aspect ratio of the lignocellulosic fibers used and their reinforcing effect (Parameter B). Symbols are the same as in Fig. 2.

Fig. 5 Evolution of acoustic signals during the tensile testing of a PLA/wood composite (10 vol\% W68); (o) individual acoustic signals, _ $\_$stress vs. strain trace.

Fig. 6 Dependence of the cumulative number of signals on deformation for the composite of Fig. 5. The corresponding stress vs. strain trace is plotted as reference.

Fig. 7 Comparison of the cumulative number of signal traces for all PLA/lignocellulosic fiber composites at 10 vol\% fiber content.

Fig. 8 Dependence of the initiation stress of the dominating micromechanical deformation process on wood content. Symbols are the same as in Fig. 2.

Fig. 9 Correlation between the characteristic stress determined by acoustic emission measurement and the reinforcing effect of the fibers in PLA/wood composites. Symbols are the same as in Fig. 2.

Fig. 10 Comparison of interfacial adhesion in various polymer/wood composites. Corrected parameter $B$ $\left(B \sigma_{y 0}\right)$ plotted against the yield stress of the matrix $\left(\sigma_{y 0}\right)$. Symbols: $(\mathrm{O}) \mathrm{CaCO}_{3}$ composites, $(\diamond) \mathrm{PP}$ random copolymer, poor adhesion, $(\diamond)$ random copolymer, good adhesion, $(\Delta)$ PP homopolymer, good adhesion, (V) PVC, ( $\square)$ PLA. 
Fig. 11 SEM micrograph taken from the fracture surface of a PLA/wood (W68) composite at 20 vol\% wood content. Fracture surface was created at failure in the tensile test.

Fig. 12 Fiber fracture in PLA model composites, POM micrographs. a) W68, b) W54, c) MC29. The composites contained 10 vol\% fiber.

Fig. 13 Competitive micromechanical deformation processes in PLA/corn cob (20 vol\%) composites. a) fiber fracture, b) fracture and debonding.

Fig. 14 Correlation between the initiation stress of the dominating micromechanical deformation process and the ultimate tensile strength of the composites. Symbols are the same as in Fig. 2. 
Table 1 Particle characteristics of the studied lignocellulosic fibers

\begin{tabular}{|l|c|c|c|c|c|}
\hline Fiber & Abbreviation & $\begin{array}{c}\mathrm{D}[4,3]^{\mathrm{a}} \\
(\mu \mathrm{m})\end{array}$ & $\begin{array}{c}\text { Length }^{\mathrm{b}} \\
(\mu \mathrm{m})\end{array}$ & Diameter $^{\mathrm{b}}$ & Aspect ratio $^{\mathrm{b}}$ \\
\hline Corn cob & $\mathrm{CC23}$ & 143.4 & 108.1 & 55.7 & 2.3 \\
\hline Vivapur MCC & $\mathrm{MC29}$ & 138.0 & 85.0 & 33.3 & 2.9 \\
\hline Arbocel CW 630 & W35 & 39.6 & 93.5 & 41.4 & 5.5 \\
\hline Lasole 200/150 & W54 & 280.8 & 167.9 & 63.9 & 6.8 \\
\hline Filtracel EFC 1000 & W68 & 213.1 & 363.4 & 21.8 & 12.6 \\
\hline Arbocel FT 400 & W126 & 171.2 & 235.2 & & 3.5 \\
\hline
\end{tabular}

${ }^{a}$ volume average particle size

${ }^{\mathrm{b}}$ average values determined from scanning electron micrographs 
Table 2 Reinforcing effect of the studied lignocellulosic fibers in PLA

\begin{tabular}{|l|c|c|c|}
\hline Fiber & $\begin{array}{c}\text { Matrix strength } \\
(\mathrm{MPa})\end{array}$ & Parameter $B$ & $\mathrm{R}^{2 \mathrm{~b}}$ \\
\hline \hline CC23 & 58.2 & 1.73 & 0.9978 \\
\hline MC29 & 54.2 & 2.17 & 0.9854 \\
\hline W35 & 60.1 & 2.44 & 0.9987 \\
\hline W54 & 58.3 & 2.05 & 0.9922 \\
\hline W68 & 55.9 & 2.23 & 0.9944 \\
\hline W126 & 58.4 & 2.56 & 0.9958 \\
\hline
\end{tabular}

${ }^{a}$ calculated from the intersection of the $\ln \sigma_{\text {rel }}$ vs. $\varphi$ lines (measured value 57.9 MPa)

${ }^{b}$ determination coefficient showing the goodness of the linear fit

Table 3 Estimation of the strength of interfacial adhesion in PLA/wood composites by various approaches; the same reinforcement (corn cob) was used in all three matrices.

\begin{tabular}{||l||c|c|c||}
\hline \multirow{4}{*}{ Matrix } & \multicolumn{3}{|c||}{ Approach } \\
\cline { 2 - 4 } & Work of adhesion & $\begin{array}{c}\text { Debonding } \\
\left(\mathrm{mJ} / \mathrm{m}^{2}\right)\end{array}$ & Parameter $B$ \\
\hline \hline PP & 82.2 & $\left.67 / \mathrm{m}^{2}\right)$ & 1.16 \\
\hline PLA & 97.7 & 93 & 1.73 \\
\hline PVC & 95.6 & 162 & 2.59 \\
\hline
\end{tabular}


GRAPHICAL ABSTRACT

GRAPHICAL ABSTRACT FIGURE

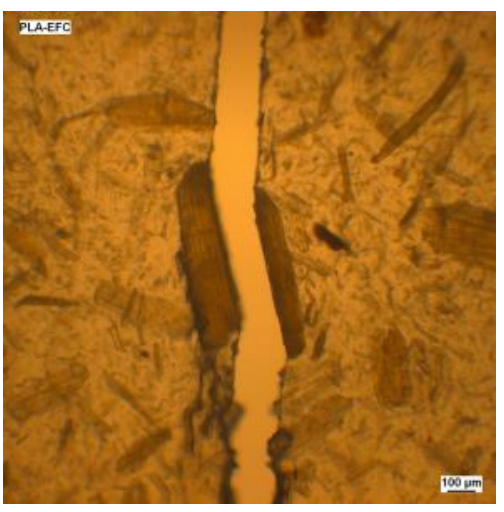


Faludi, Fig. 1

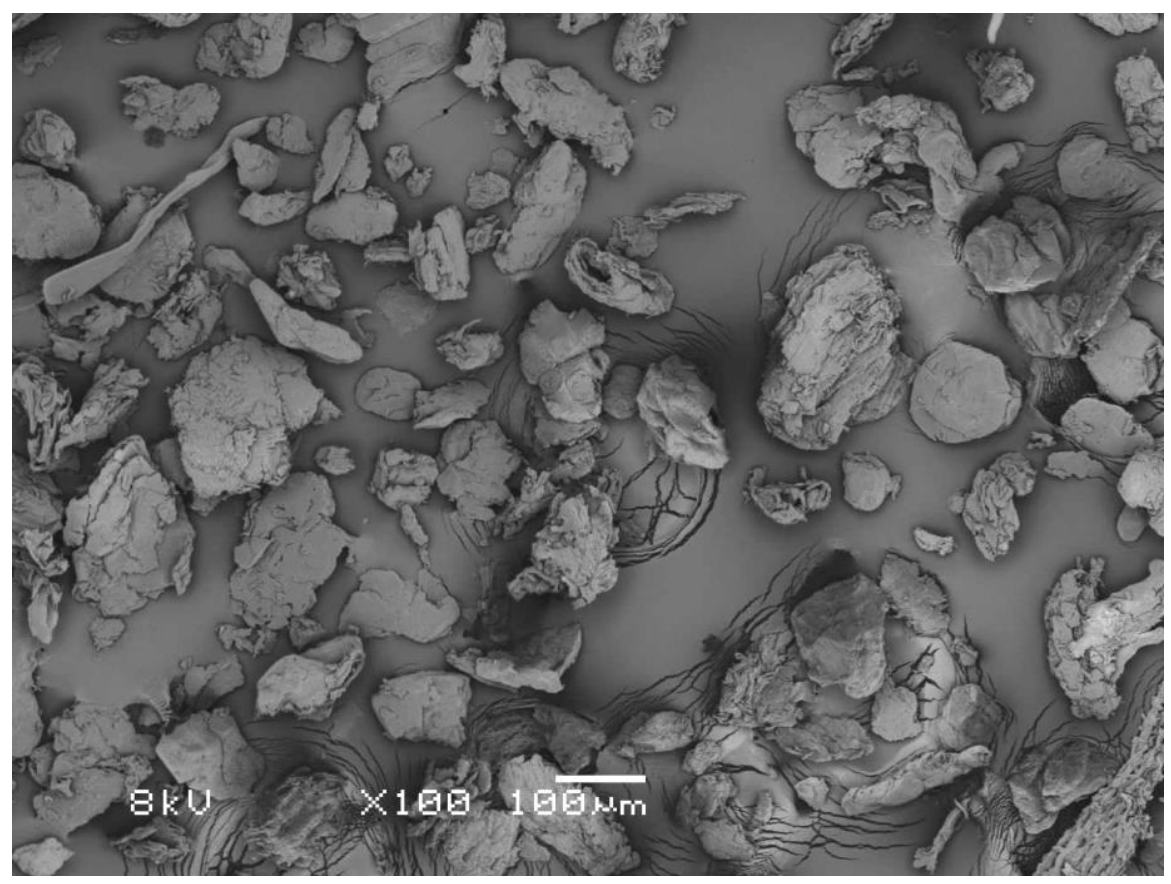

a)

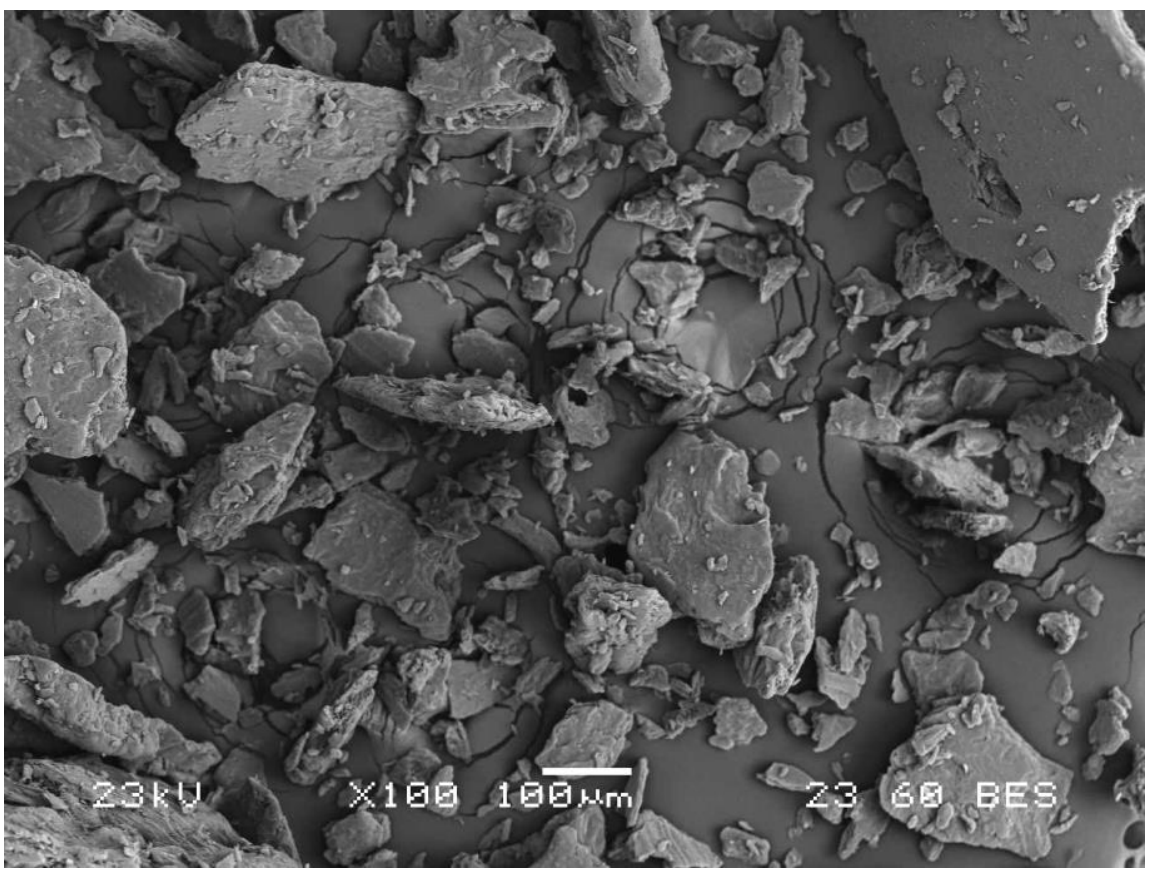

b) 


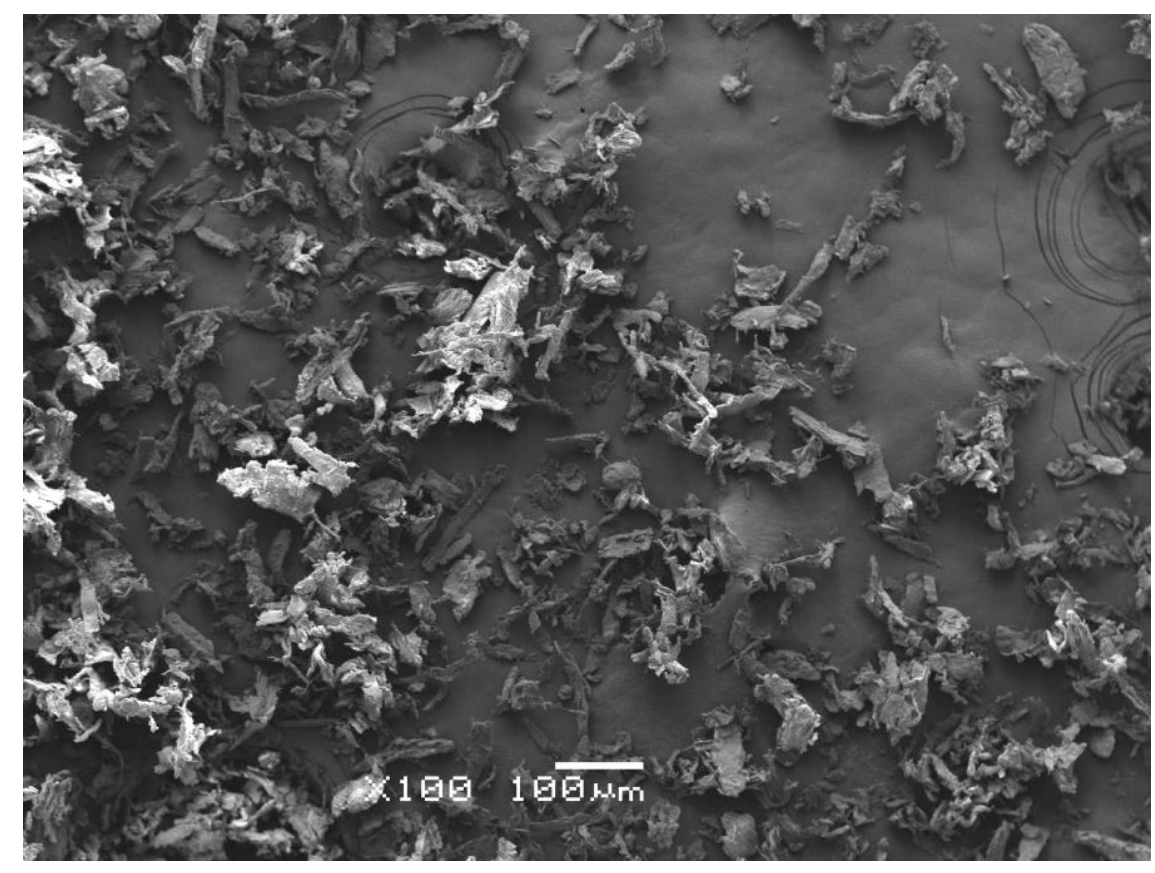

c)

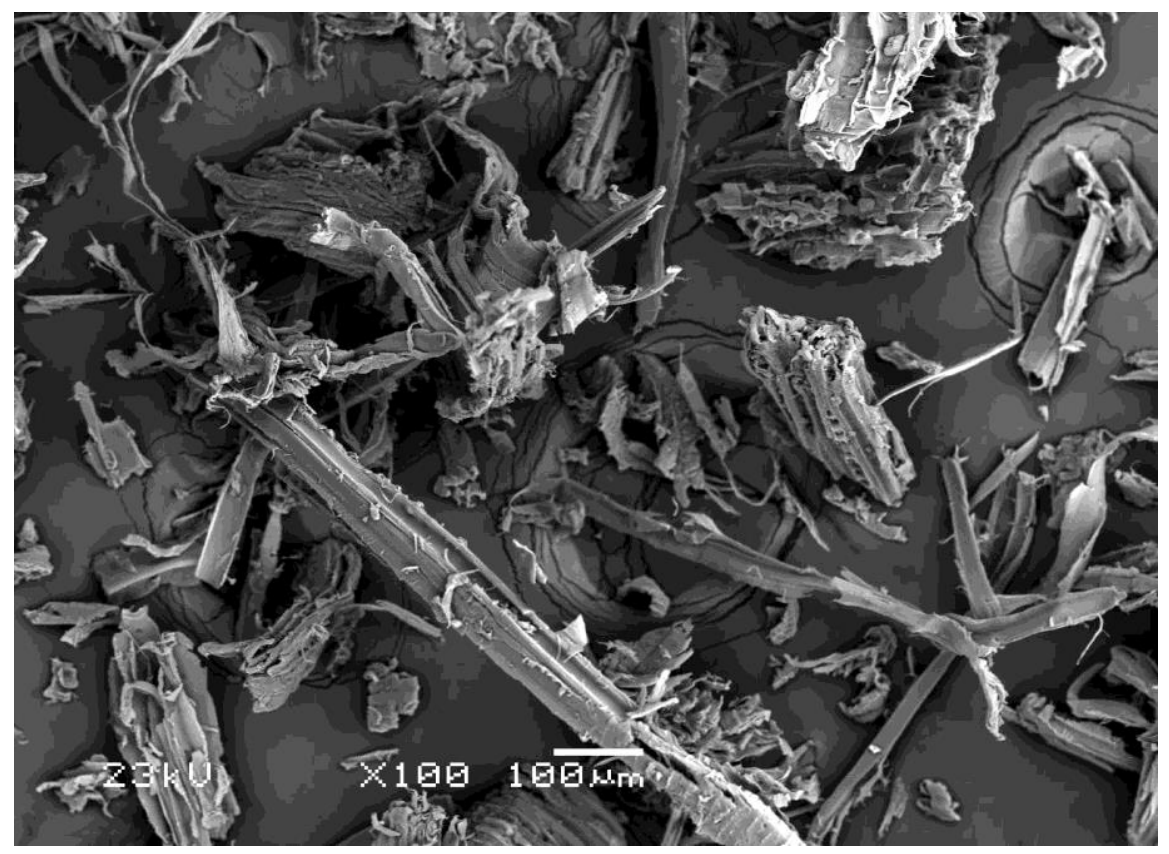

d) 


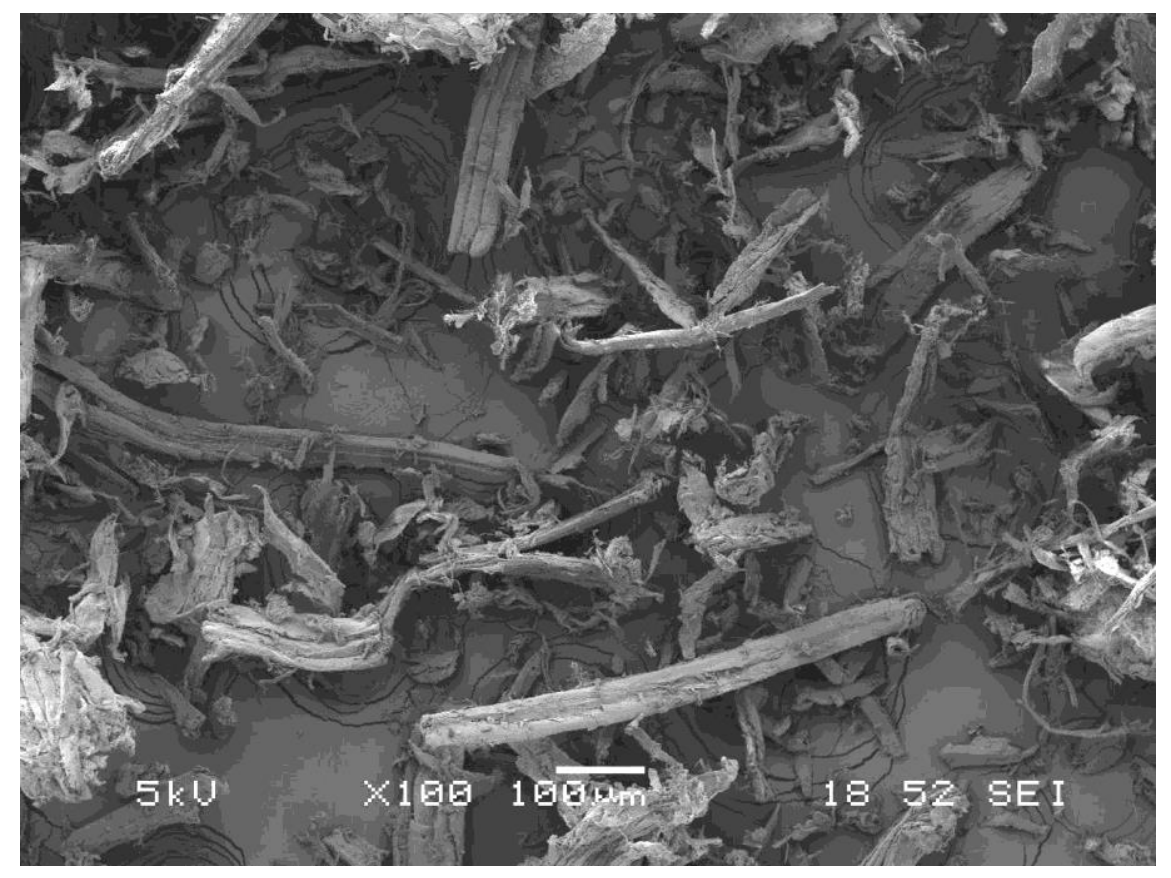

e)

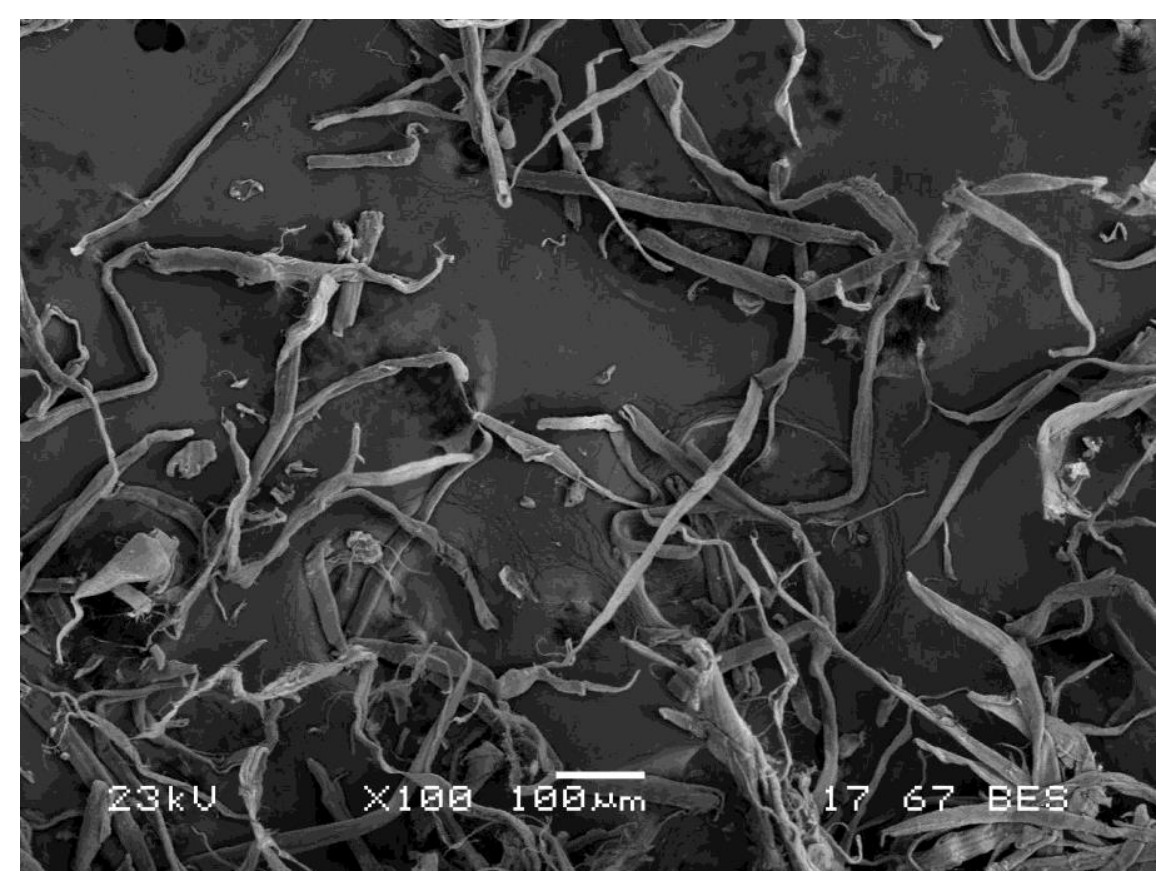


Faludi, Fig. 2

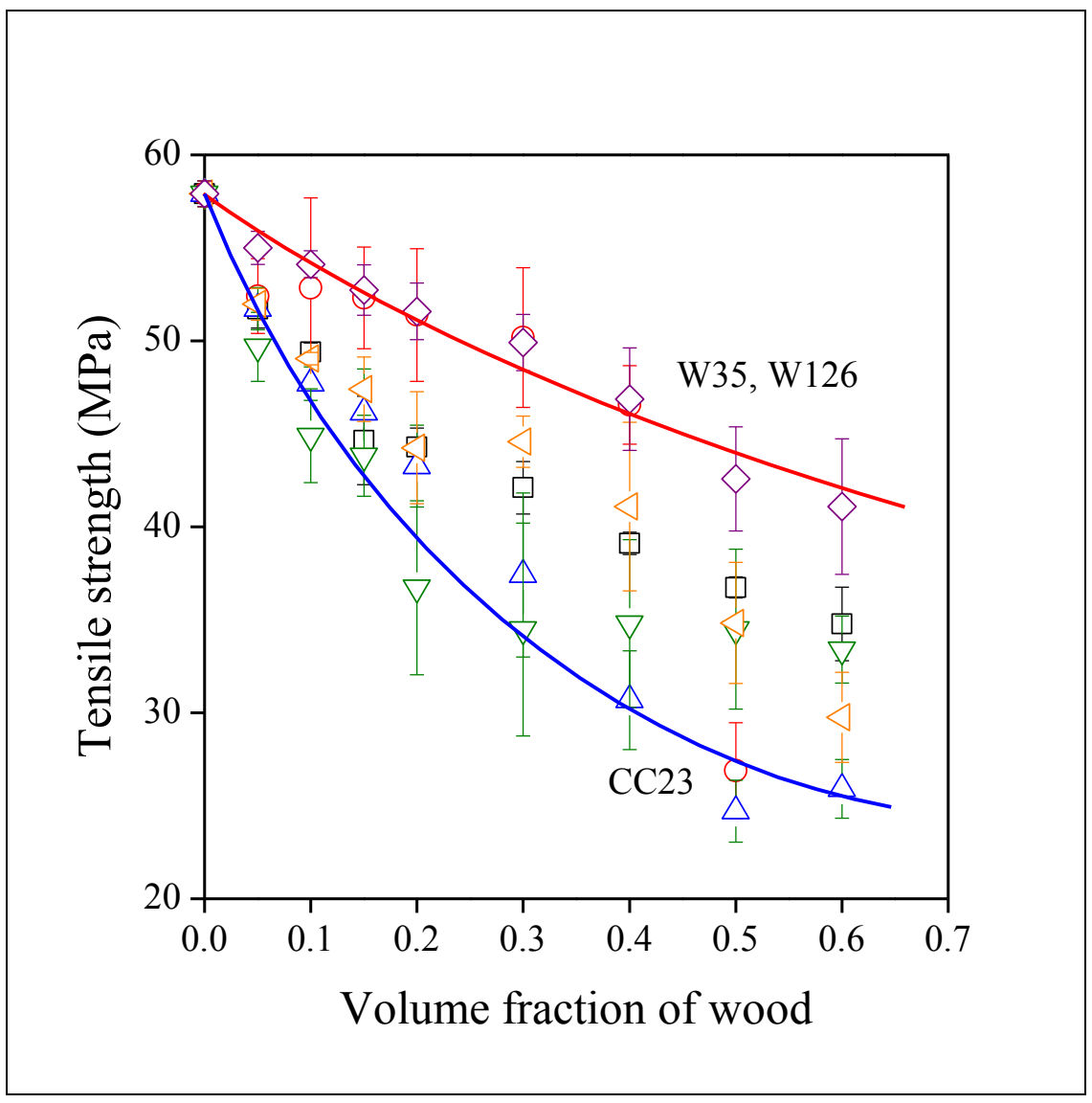


Faludi, Fig. 3

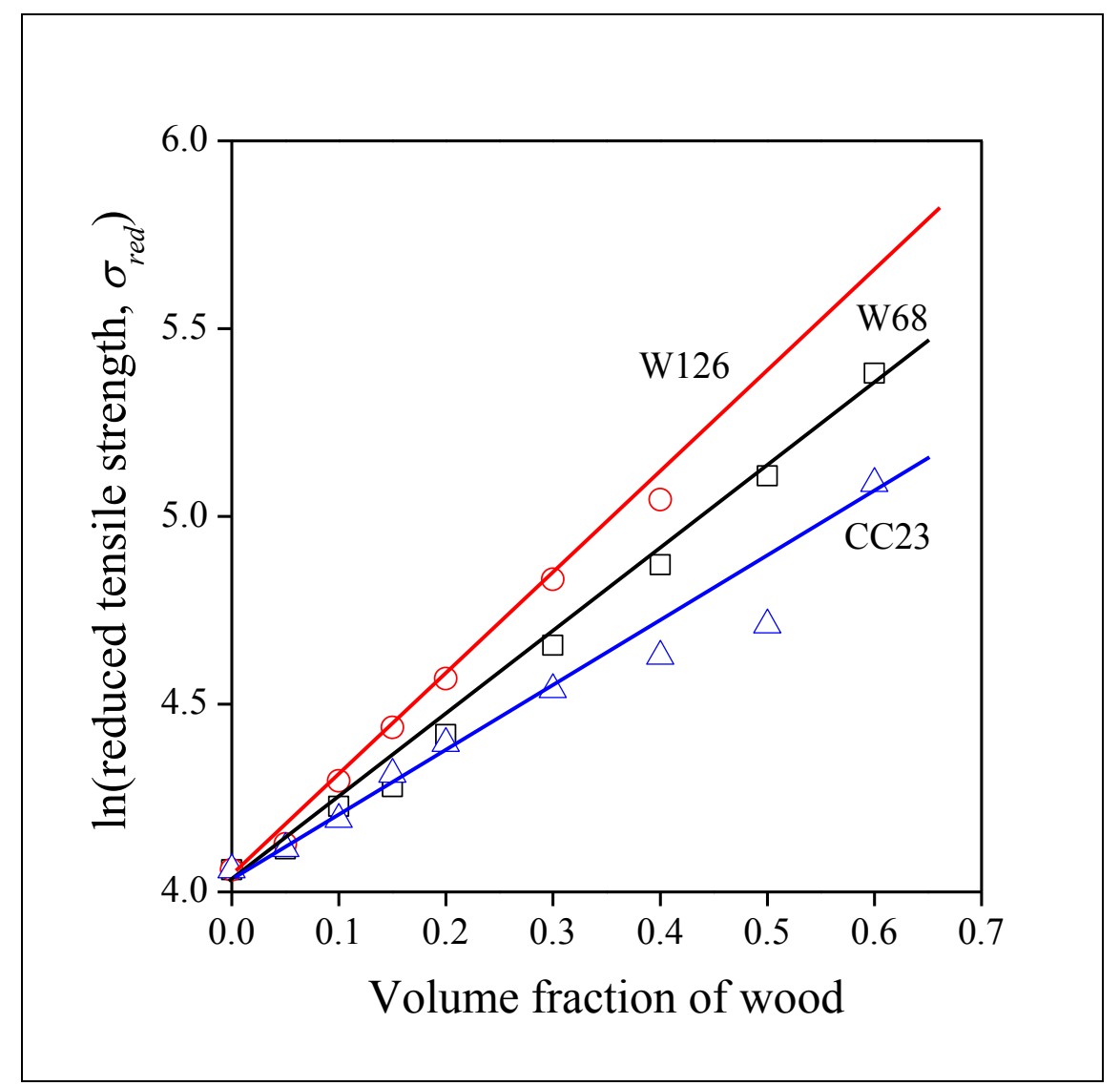


Faludi, Fig. 4

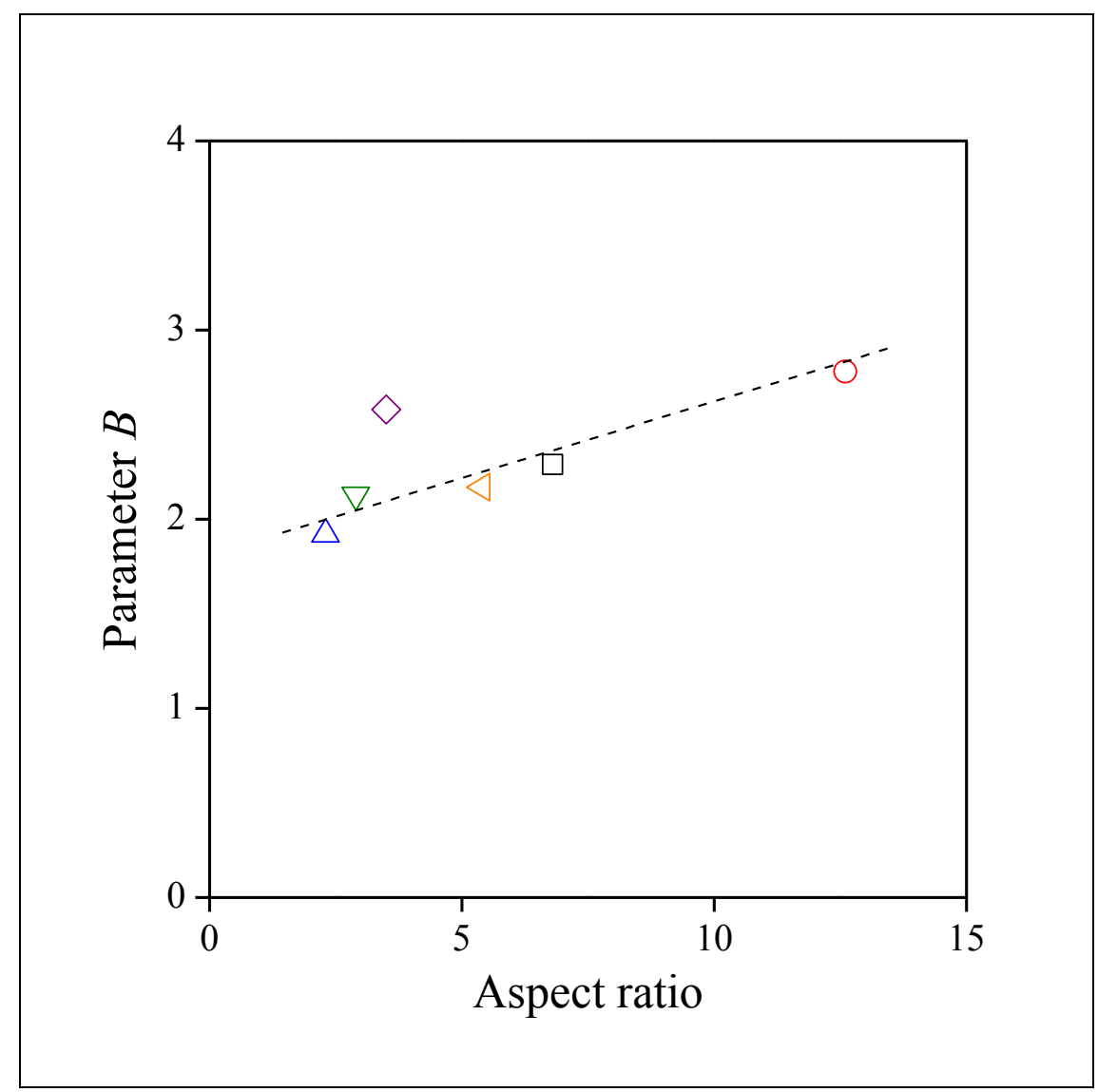


Faludi, Fig. 5

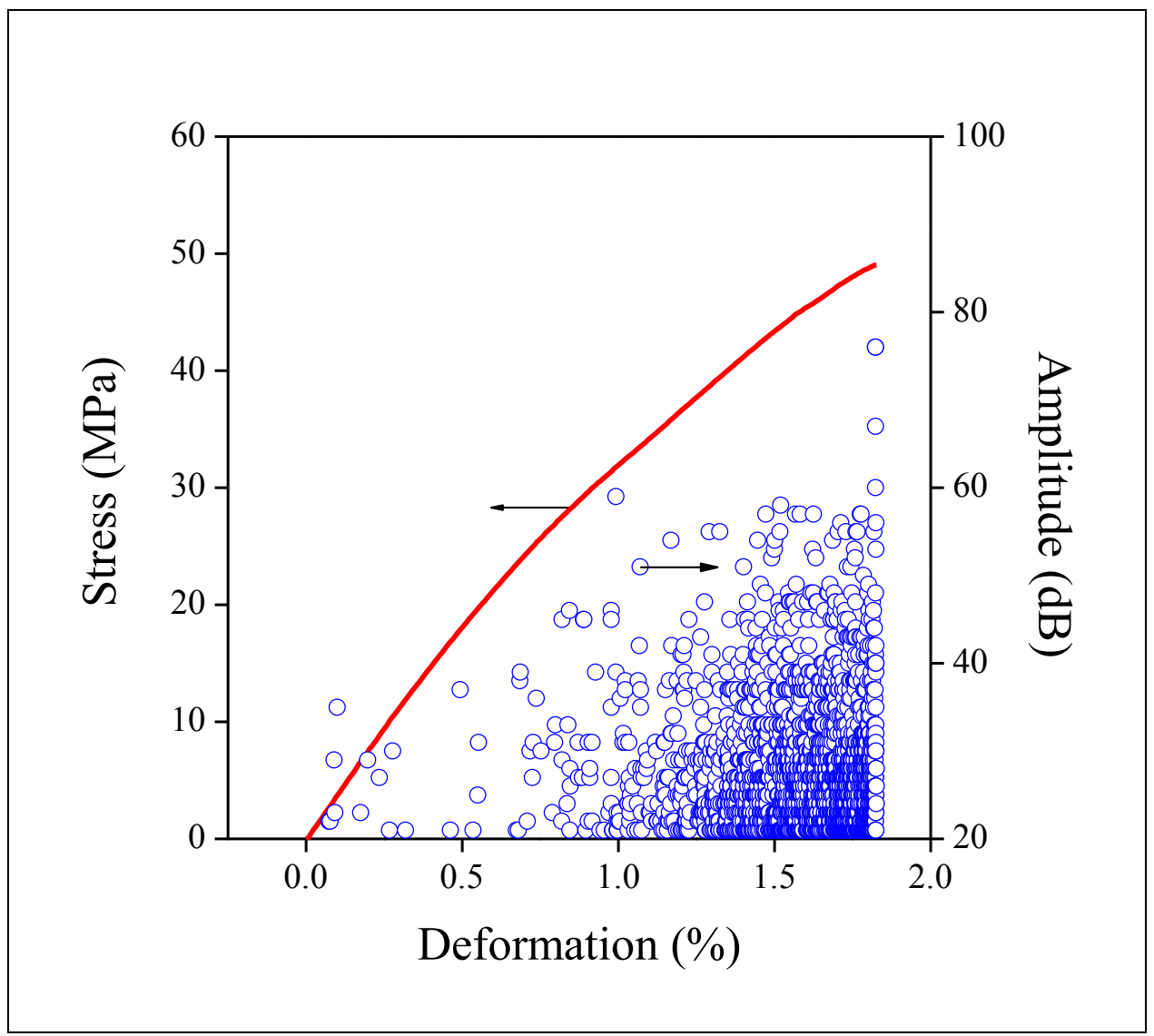


Faludi, Fig. 6

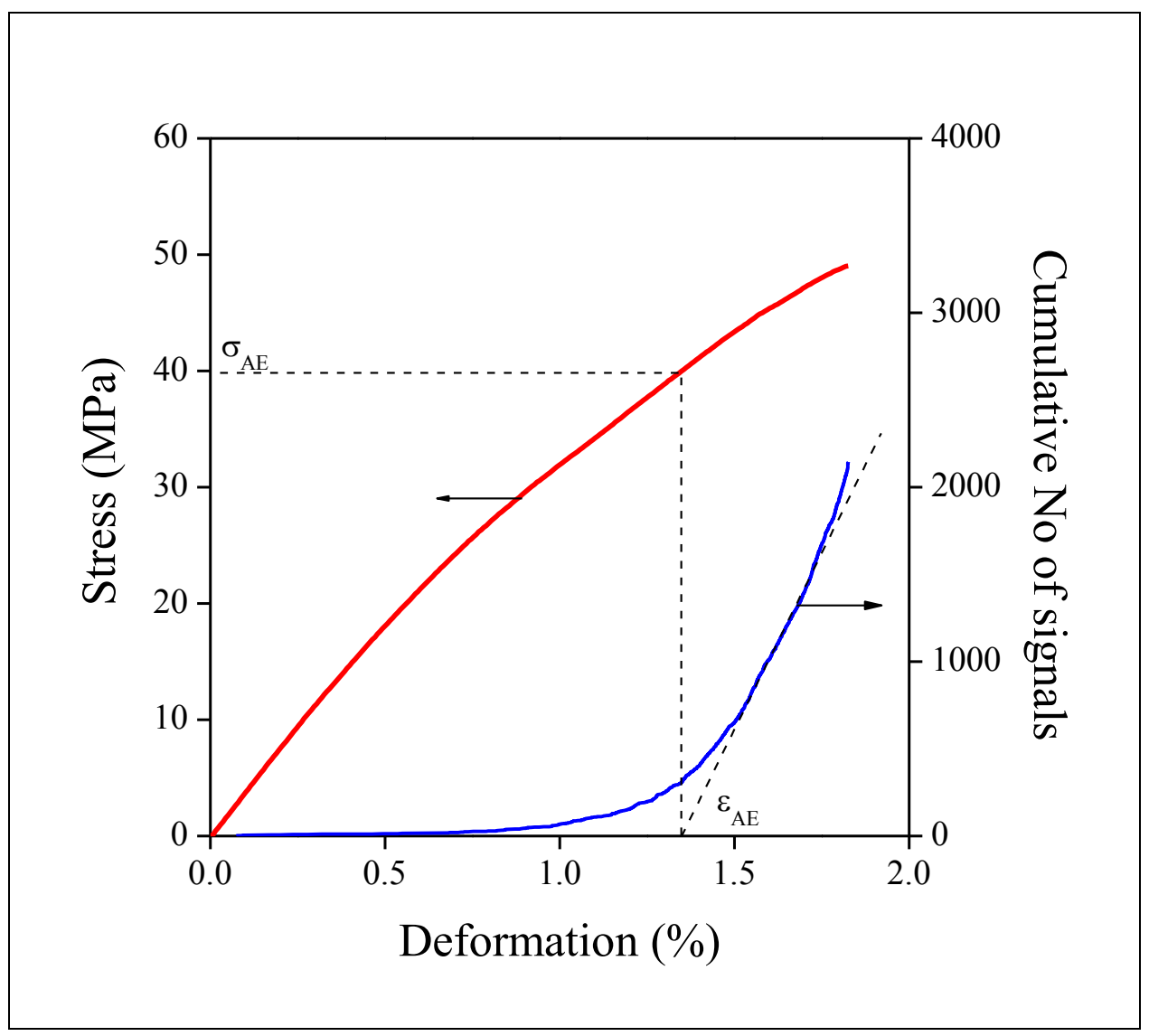


Faludi, Fig. 7

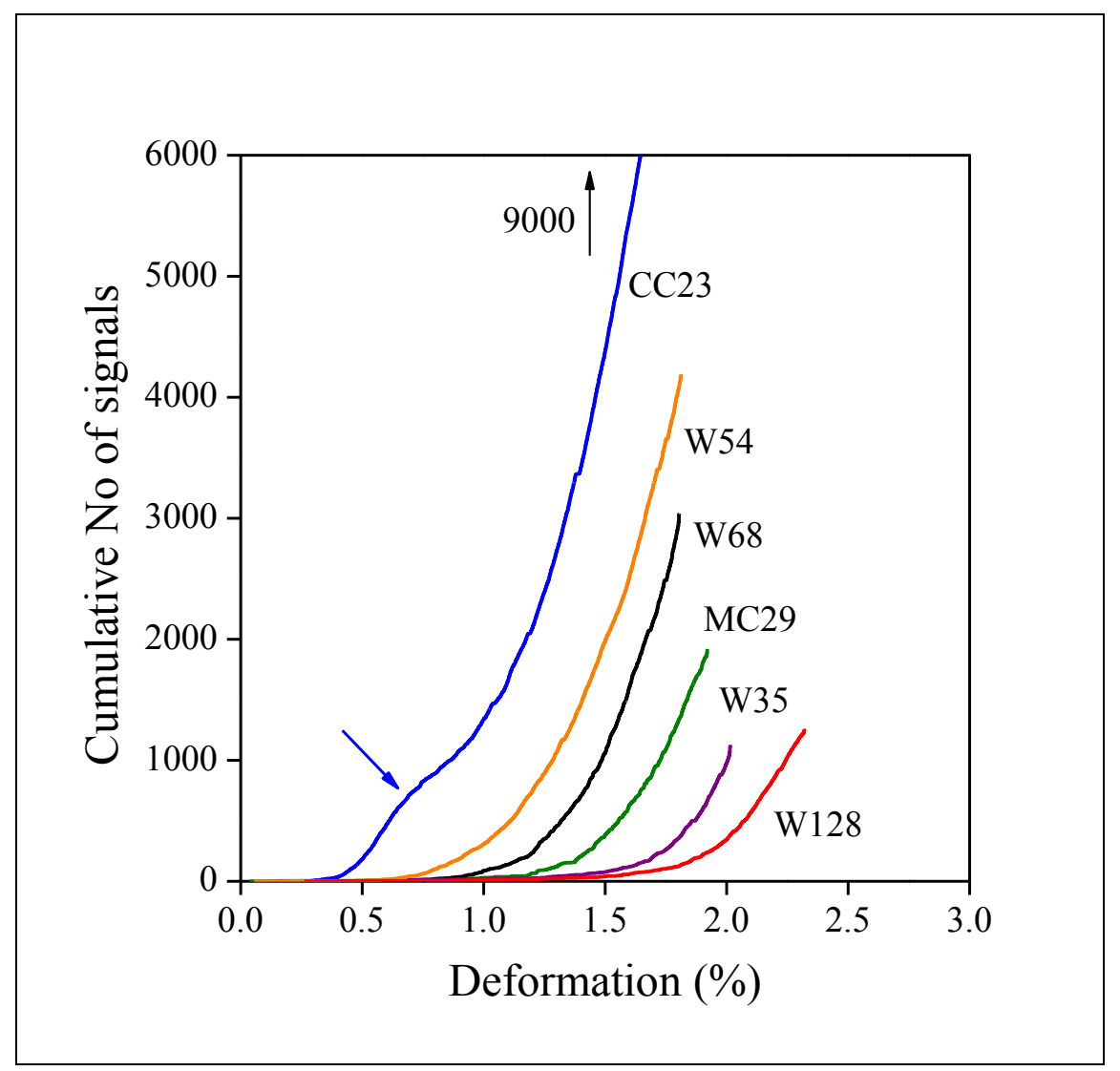


Faludi, Fig. 8

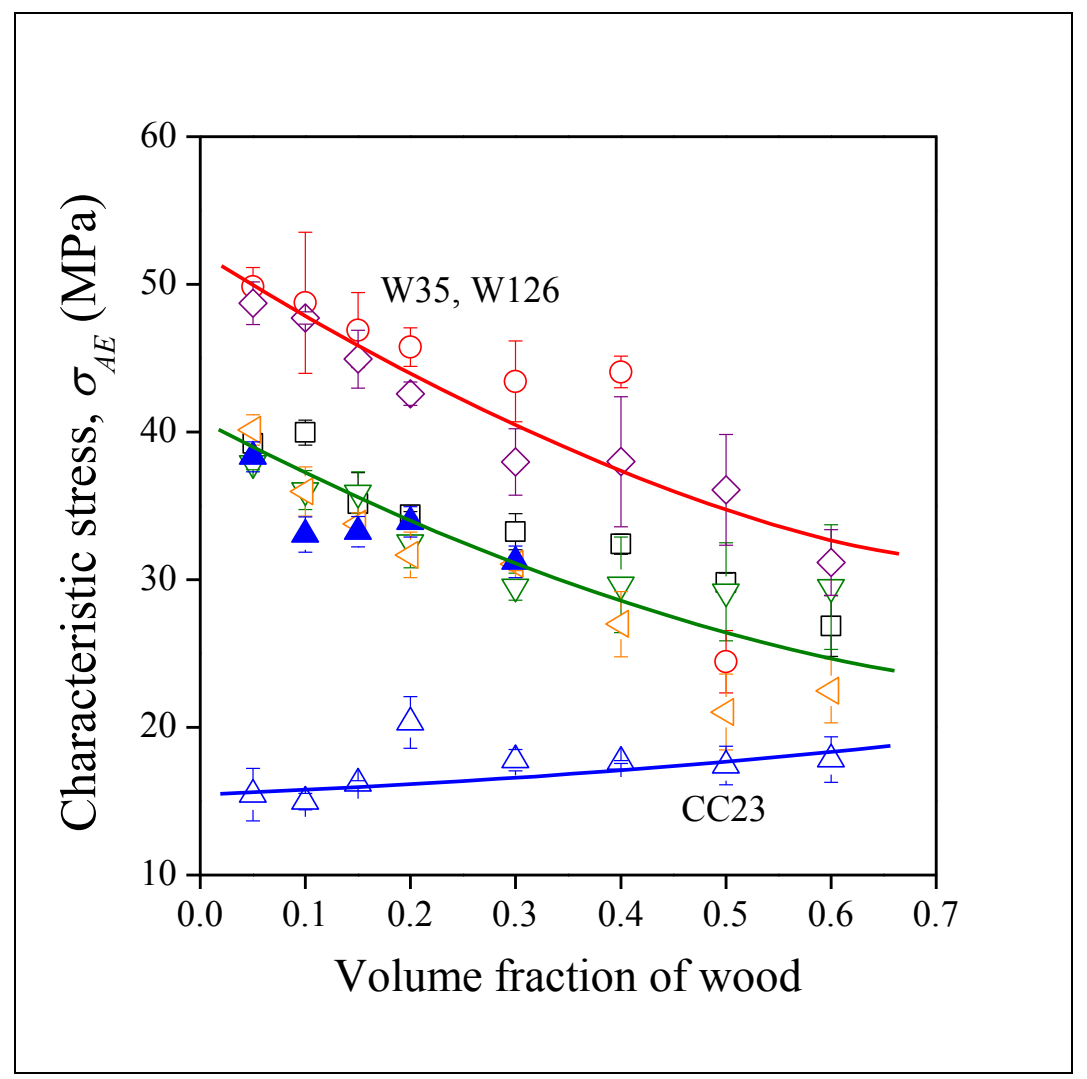


Faludi, Fig. 9

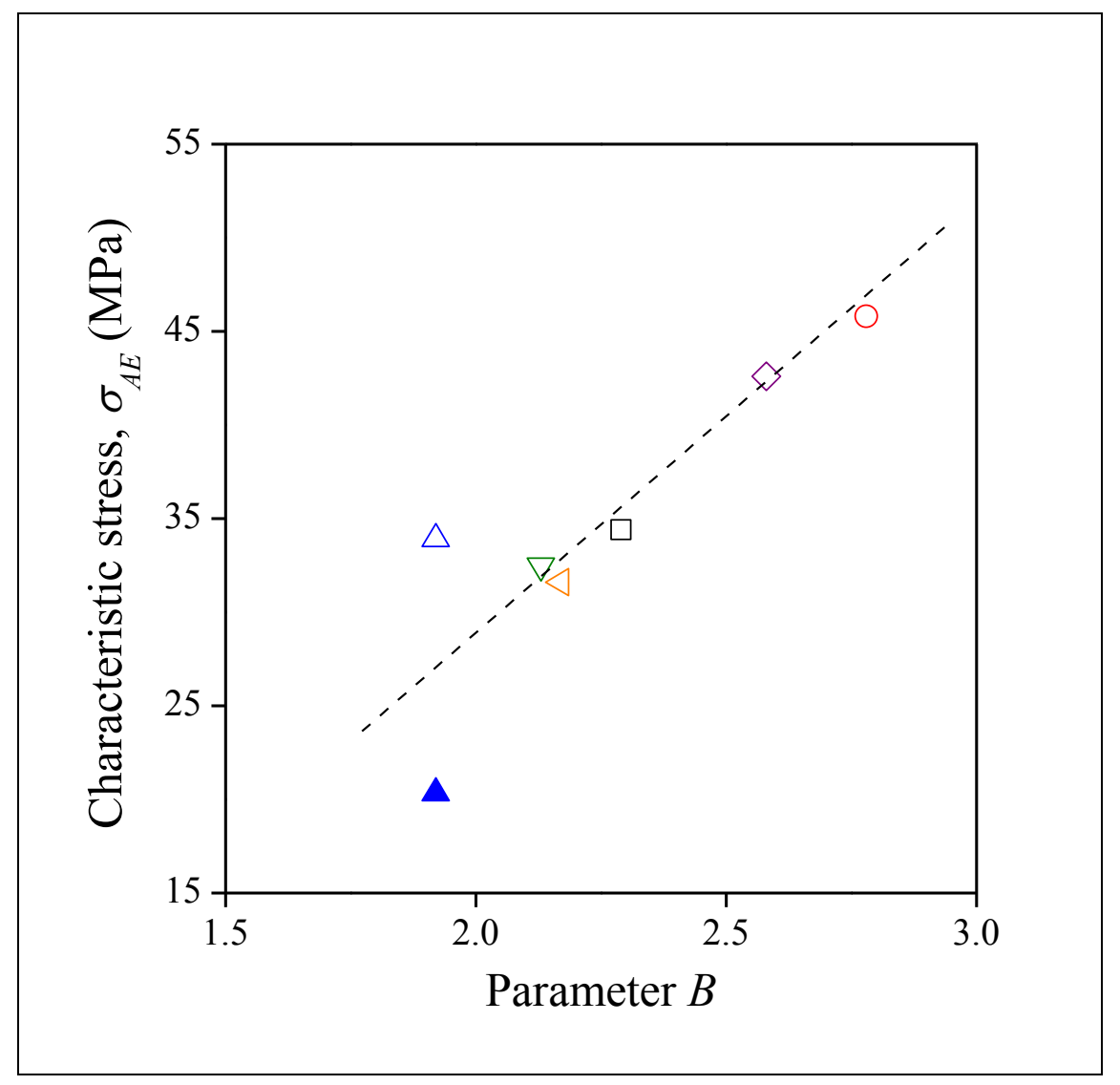


Faludi, Fig. 10

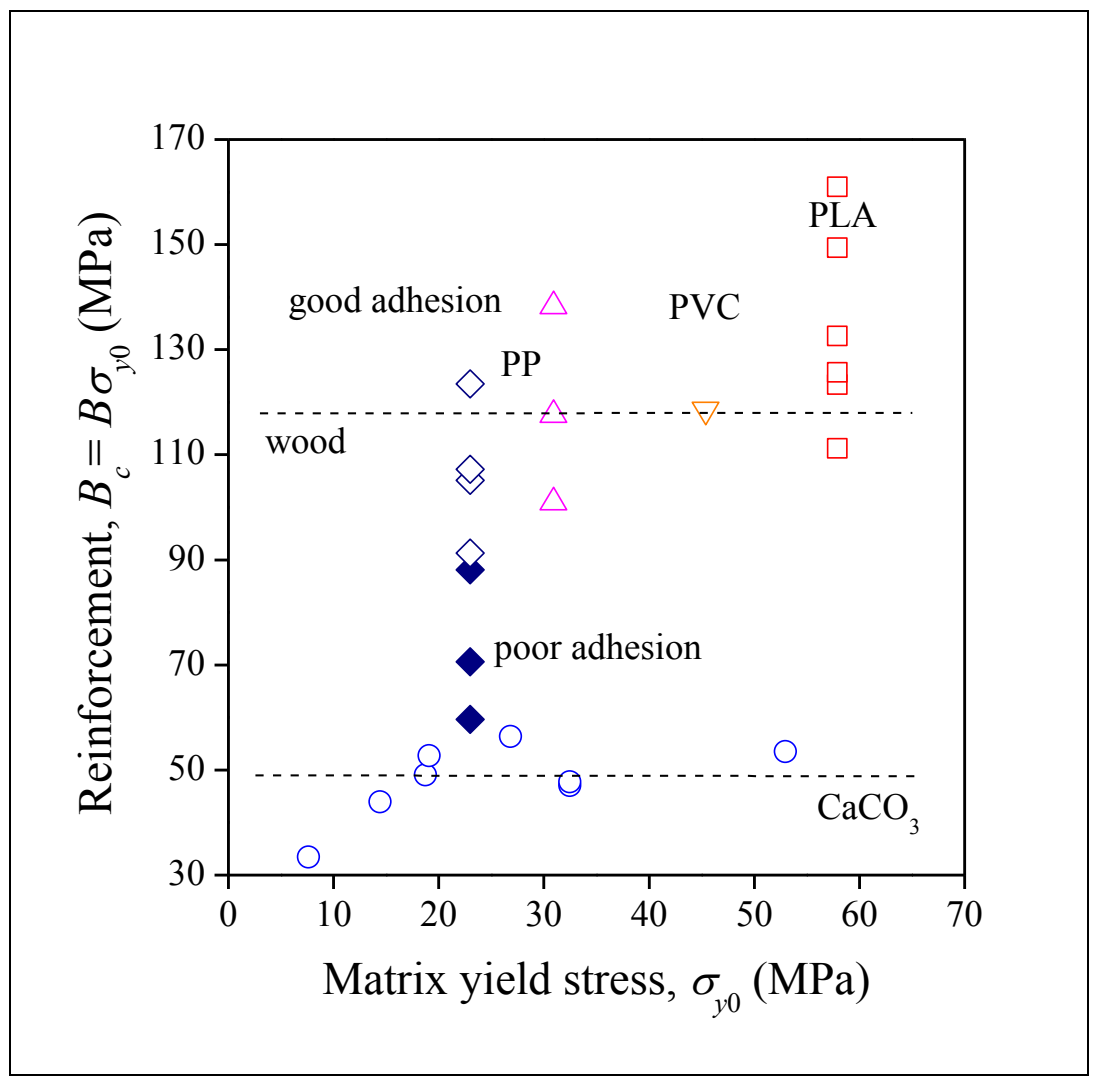


Faludi, Fig. 11

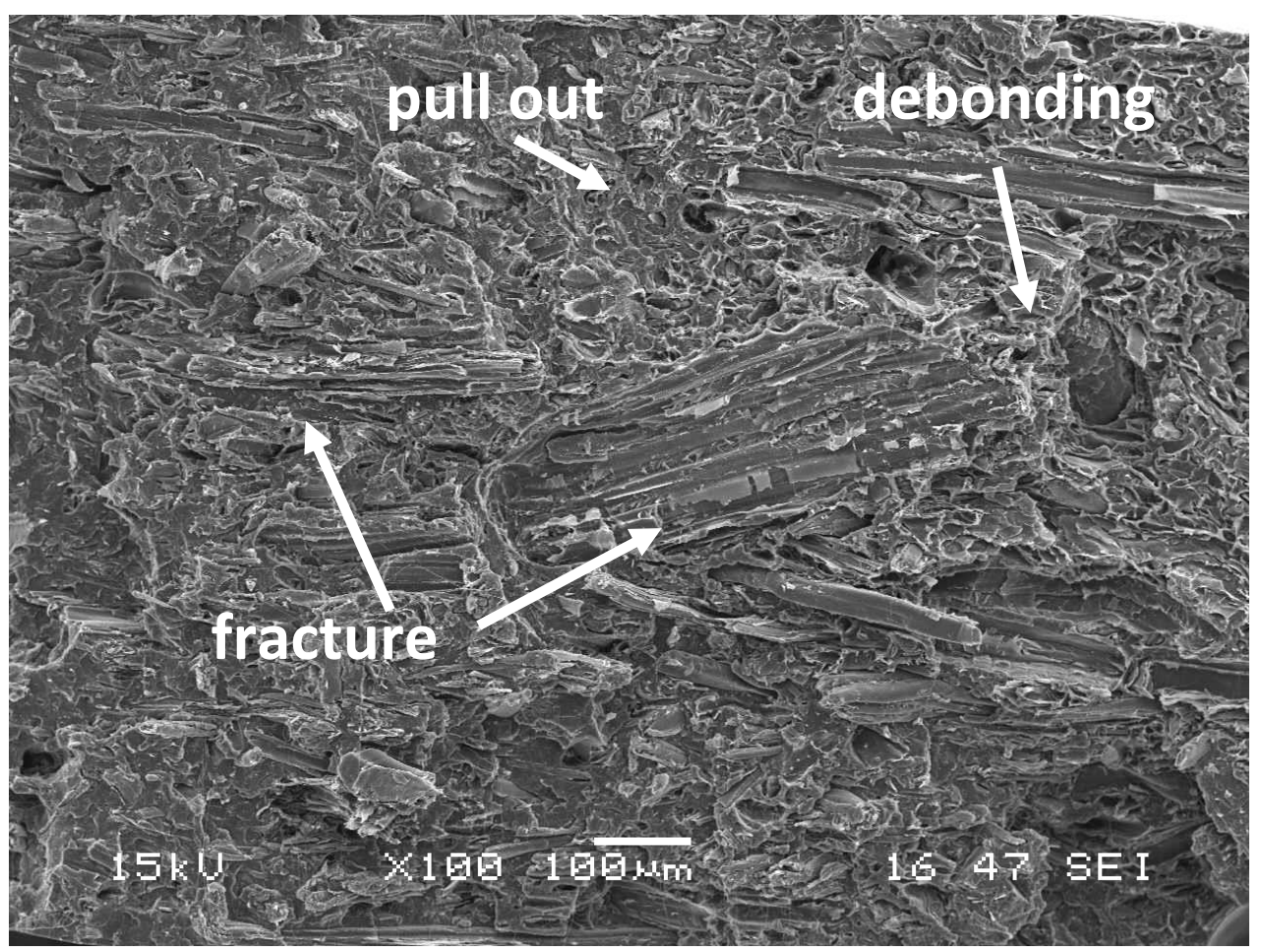


Faludi, Fig. 12

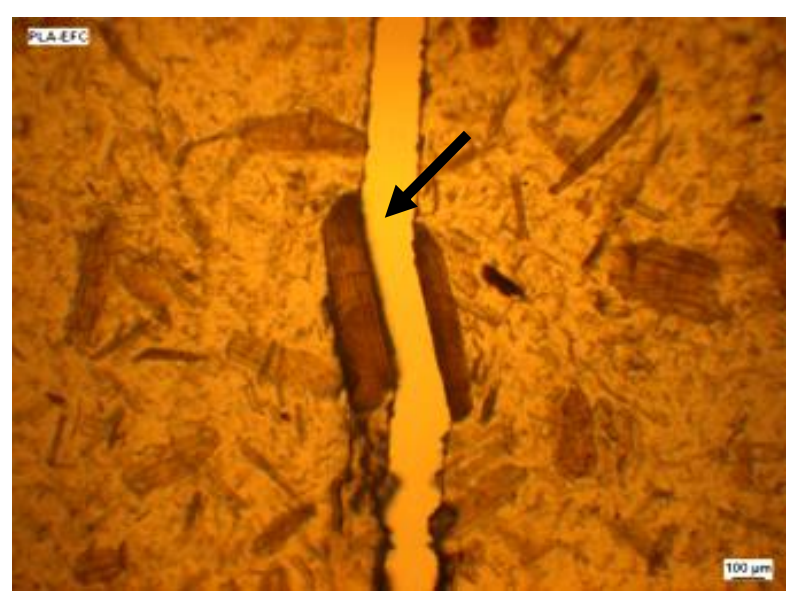

a)

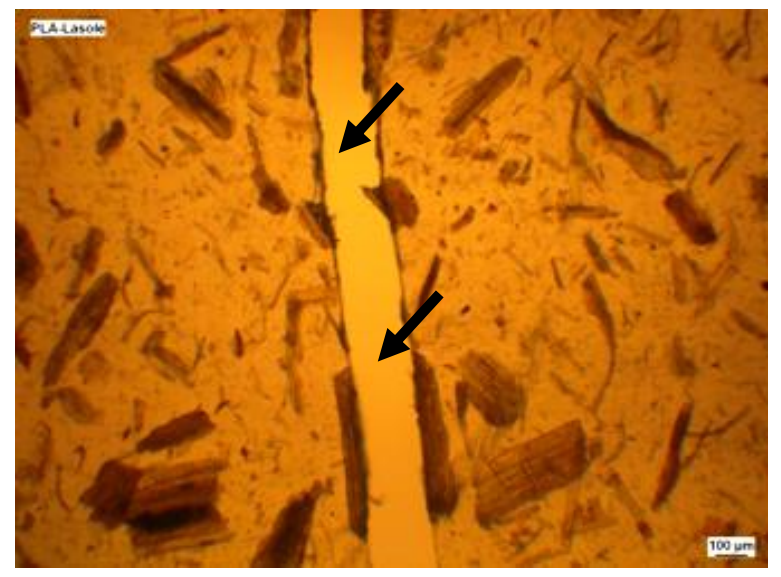

b) 
Faludi, Fig. 13

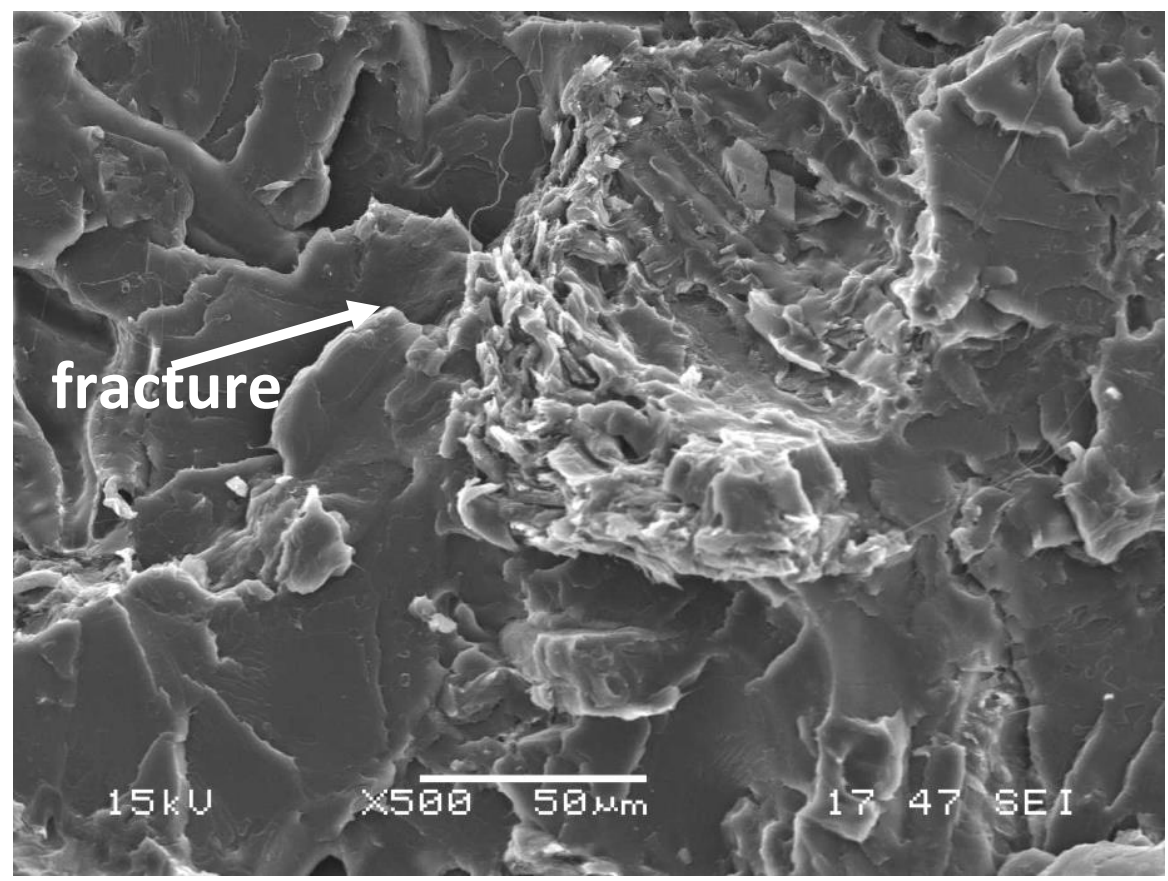

a)

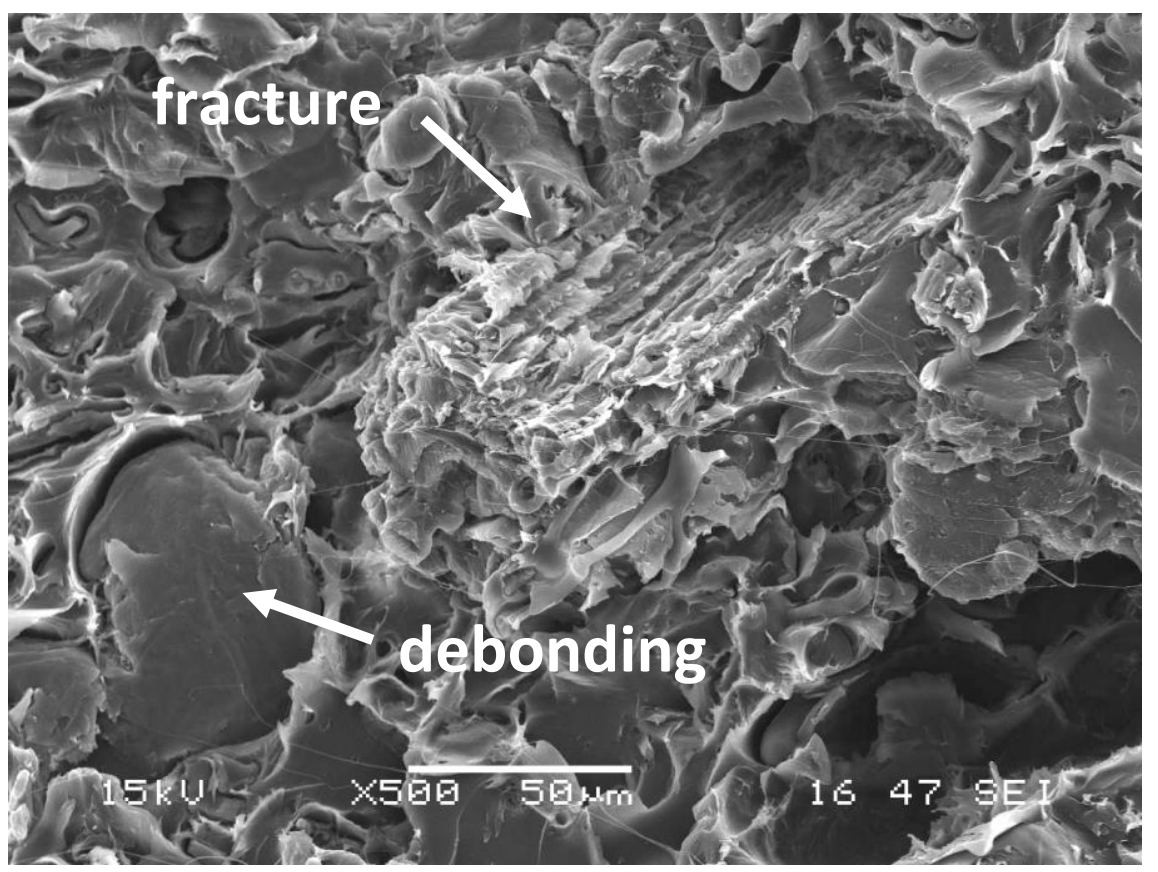

b) 
Faludi, Fig. 14

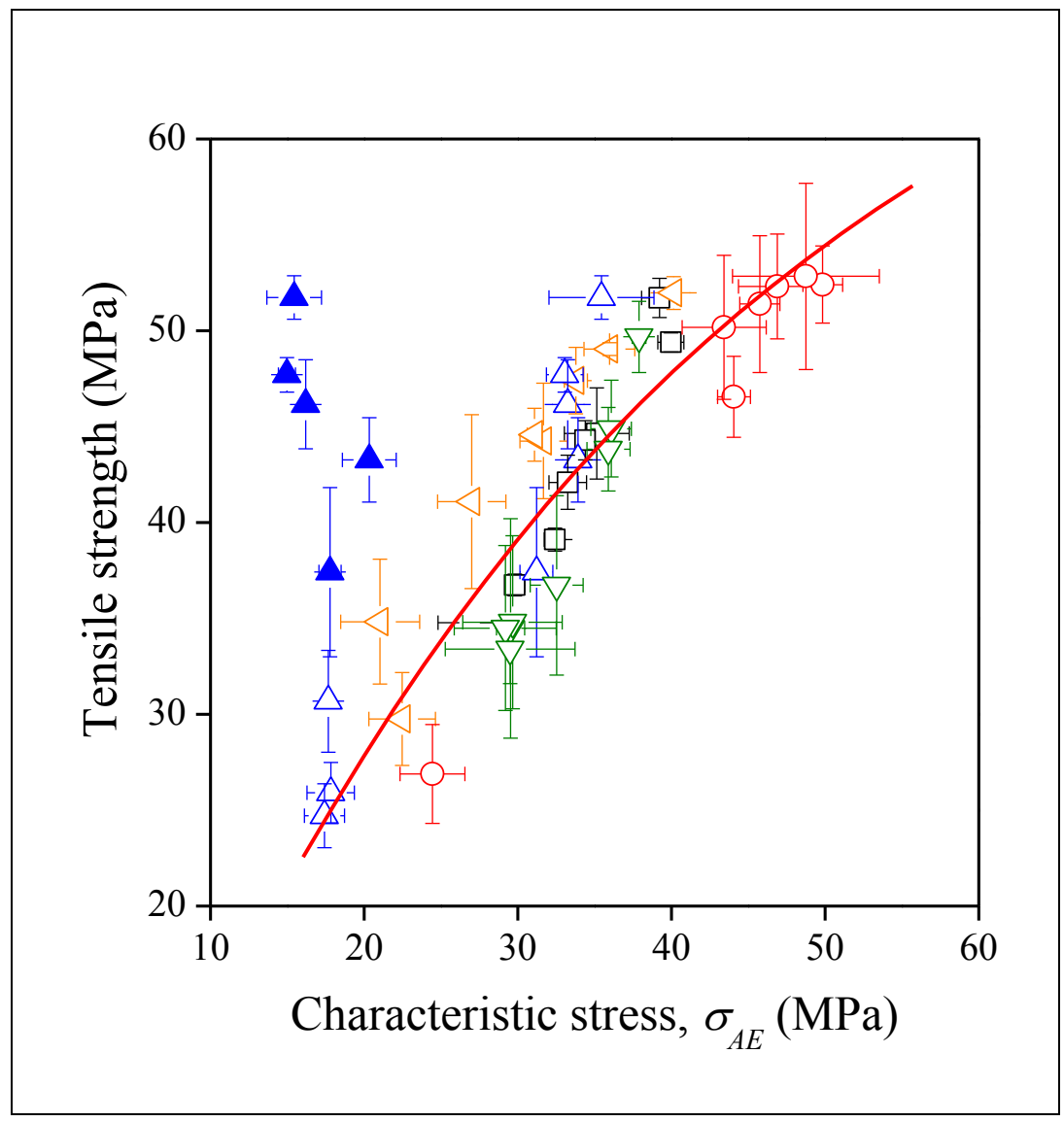

